\title{
Chapter 7 Safety principles for French research reactors
}

\subsection{General safety principles, concepts, approaches and objectives}

This chapter presents the general safety principles, concepts, approaches and objectives that have guided the design and operation of French research reactors. It also highlights changes that have been made over time, which have generally brought practices into line with those adopted for nuclear power reactors, including those of the European Pressurised Water Reactor (EPR). Several features specific to research reactors will be covered, including the most important, which involves taking into account core melt accidents in the design of some French research reactors in the 1960s.

The nuclear safety and radiological protection measures adopted for the design and operation of nuclear power or research reactors must limit the number of incidents, the potential occurrence of accidents and meet the fundamental safety objective as stated in IAEA document SF-1, which is to "protect people and the environment from harmful effects of ionizing radiation". This objective is of course entrenched in French law, and specifically in the Public Health Code (Article L. 1333-1) and in the Environmental Code (Article L. 110-1).

Design principles focus on various aspects, including the intrinsic characteristics of the reactor (e.g. core neutronics), the general architecture of systems, material redundancy and diversification, protection against internal and external hazards, radiological protection systems, the choice of coolants used and the effluent management and 
treatment measures, the choice of materials, etc. Beneficial feedback can be capitalised on by adopting proven practices for the design and manufacture of equipment. It is also important to adopt the best available techniques ${ }^{154}$ such as can be applied to the facility in question.

Document SF-1 and, in France, the abovementioned texts, the French Act on nuclear security and transparency (TSN) and the Order setting general rules regarding basic nuclear installations, also state a number of major principles, such as the primary responsibility of the operator to prevent accidents and limit their consequences should they occur, introducing the "defence in depth" principle.

The abovementioned fundamental objective is generally broken down into general safety objectives that are expressed in a qualitative manner for the various events studied for a facility, based on their estimated frequency of occurrence. For the Jules Horowitz Reactor project, these objectives were set basically in keeping with those adopted for the EPR. Therefore, for the most frequently foreseeable incidents, their consequences must not require any counter measures for the public and the environment, and also remain within the authorised limits for gaseous and liquid discharges. For the most serious accidents studied involving core meltdown, their consequences in terms of the extent and duration must only require very limited counter measures to protect the public and the environment (no permanent relocation, no emergency evacuation beyond the facility's immediate vicinity, limited sheltering, etc.). In other words ${ }^{155}$, the following must be avoided:

- early radioactive releases that would require off-site emergency measures but with insufficient time to implement them;

- large radioactive releases that would require protective measures that could not be (sufficiently) limited in area or time.

Some aspects of theses general safety objectives are developed in greater detail in section 7.1.4.

Like power reactors, research reactors present risks associated with the radioactive materials that they use. lonising radiation is released from fission reactions and by the radioactive products created by these fission reactions, or by activation. The primary channel of exposure is direct radiation from the nuclear reactor or the associated systems as radioactive sources. Several measures are implemented to provide protection against exposure (staying away from the source, use of absorbent materials such as lead, concrete or water). Another potential channel of exposure is contamination from the release of radioactive substances into the atmosphere. Measures taken to ensure that these substances are contained in normal or accident operating conditions are therefore fundamental.

154. This concept is explained in Appendix I of the Order dated 26 April 2011 pertaining to the implementation of the best available techniques, as stipulated in Article R. 512-8 of the French Environmental Code.

155. These objectives are formalised in Council Directive 2014/87/EURATOM of 8 July 2014 amending Directive 2009/71/Euratom establishing a Community framework for the nuclear safety of nuclear installations. 
Research reactor safety relies on various principles, concepts and procedures that are not necessarily specific to these types of reactors:

- installation of several physical confinement barriers between radioactive substances and workers, the public and the environment in order to contain these substances. For reactor core radioactive substances, three "barriers" are generally put in place (specific measures for research reactors will be identified later):

- fuel cladding,

- the boundary of the core cooling system or reactor pool,

- the building housing the reactor core,

- implementation of measures to ensure the three fundamental safety functions ${ }^{156}$ :

- control over nuclear chain reactions,

- removal of heat produced from radioactive substances and nuclear reactions,

- confinement of radioactive substances.

- the adoption of a redundancy or technological diversification principle for the most important safety systems (which perform the two primary fundamental safety functions), in order to achieve sufficient reliability for these systems. This is mainly the case for reactor protection and engineered safeguard systems, which are involved in defence in depth;

- the adoption of an analysis-based deterministic safety approach ${ }^{157}$ incorporating suitable conservative measures, and a number of postulated events ${ }^{158}$ (related to failures specific to the facility [including human errors], or internal or external hazards - see section 7.1.2), even though probabilistic studies can provide useful insight (see below). However, applying the deterministic approach to research reactors requires case-by-case analysis (particularly to establish the list of postulated events) due to the diverse range of designs and risks which these reactors present.

The cladding of fuel elements (plates, rods), often made of aluminium alloy, must at the very least maintain its leaktightness in situations corresponding to postulated events with the highest estimated frequency. This means that heat transfer between the fuel and coolant must be controlled (or more specifically, the ratio between the heat released by the fuel and the coolant flow), failing which, the temperature of cladding would rise irremediably, causing distortion, failure, or even melting (aluminium melts at $\left.660^{\circ} \mathrm{C}\right)$.

156. The first two of these three safety functions contribute to maintaining the confinement barriers.

157. Approach which, over the course of time, has indirectly taken into account probabilistic considerations, particularly by classifying operating conditions into categories based on the estimated frequency (or probability) of initiating events. The design rules depend on these (addition or not of a single failure, way of taking uncertainties into account, criteria to be complied with for equipment, etc.).

158. Postulated initiating events in IAEA documents, événements déclencheurs (initiating events) in French regulations. 
Furthermore, potentially major heat increases or surges could occur in the reactor core. If the chain reaction is not controlled, the energy released could cause fuel meltdown.

In a nuclear reactor, the reactivity is controlled using two types of elements:

- the intrinsic neutronic characteristics at the core, related to the type of fuel and coolant, and the core geometry (which determines neutron leakage): delayed neutron fraction ( $\beta$ and expressed in $p c m$ ), neutron feedback linked to the Doppler Effect in the fuel and the effect of dilation or contraction of structures and the coolant, etc. Several values for these characteristics are given as an example in section 7.2 for different types of research and power reactors;

- added components, mainly in the form of rods or plates made of neutron absorbing materials that can be inserted into or removed from the core manually or automatically if thresholds associated with specific reactor operating parameters are exceeded.

The design studies and choices must be such that these components ensure optimum behaviour of the reactor in the event of disturbances such as reactivity insertion accidents. The aim is to avoid a prompt criticality as much as possible ${ }^{159}$, and maintain, in shutdown situations, a significant margin (negative or deficit reactivity) with respect to a critical state, with absorbers inserted in the core (apart from safety absorbers maintained in withdrawn position ${ }^{160}$ ). Furthermore, the number of absorbers and each of their reactivity contributions must ensure that in the event of a reactor shutdown, the shutdown must be able to occur even if the most effective absorber does not drop.

\subsubsection{The defence in depth principle applied to research reactors}

A general outline of the defence in depth principle was presented in chapter 3.

However, specific features of the defence in depth principle require further explanation for research reactors:

- the first level of defence in depth seeks to prevent operating anomalies and structure, system and component (SSC) failures. This requires high quality in the design and manufacture of these SSC's and in the operation of the reactor (including preventive maintenance). Maintaining quality can require particular attention for research reactors ${ }^{161}$, for several reasons:

159. Prompt criticality occurs if the core reactivity, with counter reactions taken into account, becomes higher than the delayed neutron fraction.

160. For example, to provide negative reactivity in the event of a core loading error.

161. The information below can also apply to other nuclear facilities, such as power reactors, if plans are made to extend their service life. The level of attention to be focused on these issues must of course be adjusted according to a graded approach, depending on the risks presented by the facility in question. 
- they may have a long service life which may be requested to be extended beyond what was originally planned at the time of design,

- because of this, the risks associated with aged equipment and obsolescence can become a problem,

- the necessary recruitment of new operating personnel entails risks of knowledge not being properly passed on. This can lead to operating errors and even significant events ${ }^{162}$,

- research reactors can experience phases of non-use with reduced monitoring and maintenance operations,

- for the second and third levels of defence in depth, the low pressure of reactor coolant in most research reactors means that safety injection systems do not need to be installed ${ }^{163}$. The Jules Horowitz Reactor is the only research reactor with this type of system due to the power density in the core and the coolant pressure (a dozen bars at the core inlet). For many research reactors, their intrinsic characteristics allow them to be cooled via natural convection;

- for the fourth level of defence in depth, for many research reactors, a design-basis accident with fuel melt was adopted for the design or verification of a suitable design $^{164}$ of the reactor pool, the reactor building superstructures and the ventilation and filtration systems. This subject is covered in further depth later in this chapter.

Some research reactors have also been built in areas that have gradually become more urbanised. This increases the attention that needs to be focused on reducing the consequences of accident situations and ensuring that emergency plans are suitable. This can be a prerequisite for their continued operation.

In France, various design and construction codes can be used or serve as a reference (for those formally addressing pressurised water reactors) for a project to build a research reactor and its associated systems, or for modifications to be made to an existing research reactor (new experimental system, modifications made under a safety review, etc.). In this regard, the RCC-MRx design code, developed by the CEA and manufacturers, has been applied to the mechanical equipment of the Jules Horowitz Reactor (see focus below). The RCC-E (design and construction rules for electrical and I\&C components of PWR nuclear islands), and RCC-CW (design and construction rules for civil works in PWR nuclear islands) can serve as references for research reactors.

162. This concern in particular involved the PHENIX reactor when it returned to operation in the early 2000 s after a long period of being shutdown for renovation and safety improvement work. Due to the unique nature of some research reactors, maintaining knowledge and skills on site is equally essential for aspects related to design, construction and commissioning tests.

163. Even though research reactors have reactor makeup water systems or water capacity communication systems.

164. Due to the potential radiological impacts of such an accident. 
\#FOCUS

\section{Codified design and construction rules for mechanical compo- nents, particularly in research reactors: the $\mathrm{RCC}-\mathrm{MRx}^{165}$}

The RCC-MRx “code" results from the merger of two documents in 2009:

- the RCC-MR, developed in 1985 for sodium-cooled fast neutron reactors (reactors operating at high temperatures of up to $500^{\circ} \mathrm{C}$ under normal operation);

- the RCC-MX, developed in 1998 by the CEA, AREVA-TA and AREVA-NP for the specific needs of the Jules Horowitz Reactor project (reactor and its associated experimental auxiliary systems). It can also apply to the design and construction of components or systems for research reactors in operation.

The RCC-MRx extends the potential scope of application to nuclear fusion reactors (e.g. ITER project). It provides rules for mechanical components involved in areas subject to significant creep (fast neutron reactors) or significant irradiation (fast neutron reactors, research reactors and their experimental devices). It provides the mechanical characteristics for an extensive range of materials (steel, 800 alloys, aluminium and zirconium alloys that meet the neutron transparency needs for research reactors), design rules for thin shells and box structures, and new welding processes (electron beam, laser, diffusion, etc.).

The 2015 version of the RCC-MRx reflects feedback from the use of previous editions, particularly in current projects, such as the Jules Horowitz Reactor. This includes feedback on inspection and welding procedures for aluminium processes.

The edition was developed and updated with special attention paid to consistency between the RCC-MRx and other reference documents that interact with the code, including RCC-M, official French legislation and European and international standards.

Some of the subjects covered by the RCC-MRx are given below.

\begin{tabular}{|l|}
\hline 1. \\
INTRODUCTION \\
- Scope of the code \\
- French ESP/ESPN regulations \\
-. \\
\hline 2. MATERIALS - GRADES, PRODUCTS, PROCUREMENT \\
- Material selection \\
- Product procurement conditions
\end{tabular}

165. According to the AFCEN website. This section makes reference to the 2015 version of the RCCMRx, which was the most recent edition at the time writing. 


\section{DESIGN - ANALYSIS}

- General design rules

- Design by analysis

- Design rules for shells-vessels, supports, pumps, valves, piping, bellows, box structures, heat exchangers

4. PROPERTIES OF MATERIALS (APPENDIX A3) AND WELDED JOINTS (APPENDIX A9)

5. EXAMINATION METHODS

- Mechanical, physical and chemical tests

- Ultrasonic examination

- Radiographic examination

- Liquid penetrant examination

- Leak detection methods

6. WELDING

- Acceptance of filler materials

- Qualification of filler materials

- Welding procedure qualification

- Qualification of welders and operators

- Technical qualification of production workshops

- Production welds

- Weld deposited hardfacing on steel

- Mechanical tests

- Special provisions of aluminium and zirconium alloy welding

7. FABRICATION

- Marking procedure

- Cutting - repair without welding

- Forming and dimensional tolerances

- Surface treatment

- Cleanliness

- Brazed and bolted mechanical joints

- Heat treatments

- ... 


\subsubsection{Events selected for the design and safety demonstration of research reactors}

The design of a research reactor and its related safety demonstration is based on the identification of all events (internal failures, internal and external hazards) which could affect the facility. However, depending on the event in question, the estimated frequency of the event is more or less high. For example, complete failure of a pipe is considered less likely than a moderate leak from the pipe.

For the oldest research reactors, a small number of events related to internal failures specific to equipment or operator errors were selected. These have an envelope nature and are broadly broken down into three major categories - normal events, incidents and accidents.

For the most recent research reactors or for safety reviews of the oldest research reactors, in line with practices applied for power reactors, a number of envelope "operating conditions" (up to several dozen) are adopted and classified into four categories based on the estimated frequency of the "family ${ }^{166 " ~ o f ~ i n i t i a t i n g ~ e v e n t s ~ t h e y ~ c o v e r . ~}$

Table 7.1 , at the end of this section shows the different categories of operating conditions with some of the operating conditions of a neutron beam reactor given as examples.

Different "operating conditions" are studied to determine various thermomechanical loads on the components of the facility, called design basis situations, which are also divided into categories. Component design involves checking or ensuring that the design choices made comply with design and construction code criteria (e.g. RCC-MRx) selected based on the design basis situation studied. The criteria selected also depend on other considerations such as the component's importance for safety (its safety classification) and its role (whether active or passive) in the situation in question.

"Service limits" for the core fuel of a research reactor are generally associated with the various operating condition categories. Particular attention must be paid to ensuring that $1^{\text {st }}$ and $2^{\text {nd }}$ category operating conditions (normal operating conditions and frequent transient conditions) do not cause cladding leakage or fuel melt.

The approach involving operating condition categories was not really put into practice for research reactors until the 2000s. The first case where it was actually applied was with the CABRI reactor, involving the installation of a pressurised water loop and a complete safety review of the reactor. The same approach was then used in preparing the construction licence application for the Jules Horowitz Reactor.

One of the specific features of research reactors concerns the establishment of first category, or normal operating conditions. Besides the stable operation of the reactor and normal startup and shutdown transients for the reactor, all the normal transients associated with the planned irradiation experiments should be taken into account. This is because during the basic design phase for a research reactor, the designer or operator

166. Events linked to the neutron reactivity of the core, events linked to reactor cooling, etc. Table 3.3 in the first section shows events grouped into families. 
does not always have sufficiently detailed information on the experiment programme that will be carried out. The chosen approach therefore involves defining a sufficiently broad envelope of normal transients for the potential experiments, in terms of changes over time, for the reactor, fluid temperatures in the reactor's various systems, pressure in these systems, fluid flows, neutron flux in the core, etc.

Furthermore, to establish the list of incidents and accidents that can occur in a research reactor, or second, third or fourth category operating conditions, the potential failures or errors that could occur during experiments and impact the reactor itself must be taken into account. This can raise some problems if the various types of experimental systems for the reactor have not yet been fully defined.

Various technical exchanges took place in the 2000s between the CEA, ASN and IRSN concerning interactions between a research reactor and its associated experimental systems when the CEA was developing its own design guidelines for experimental systems. For ASN, creating these guidelines was a condition for establishing an internal authorisation system $^{167}$ at the CEA. The aim of the guidelines was to formalise several major principles and an analysis approach to be used specifically for designing experimental systems based on various information. This included potential risks posed by the system, the number and robustness of "barriers" separating the test area within the system and the reactor core ${ }^{168}$, and gripping and hold-down mechanisms ${ }^{169}$ for the system.

In the guidelines, as established in January 2007, the recommended analysis approach was based on a "lines of defence" concept ${ }^{170}$. The guidelines also define the rules allowing the CEA to internally authorise the installation of a new experimental system in one of its research reactors.

The guidelines generally improved and facilitated analysis and safety inspections for experimental systems. Although the ASN did not issue a formal opinion on the guidelines, even though it was involved in work meetings and discussions on it, it recognised them by authorising the CEA to implement and organise its internal authorisation system.

The foregoing only concerns the operating safety of the reactor (with its experimental systems). It is important to remember that the reactor environment can be a source of hazards that can affect facilities. Two types of hazards must be considered - internal hazards, which originate within the facilities, such as a fire, and external hazards, such as an earthquake or airplane crash. All the potential sources of hazards must be identified and covered for the design of the reactor and associated safety demonstration. External

167. Concept already covered in section 3.6 in the first part of this document.

168. With one of the constraints being to obtain a sufficiently transparent neutron separation between the reactor core and the test area.

169. For example, this concerns experimental systems that are likely to increase core reactivity in the event of unplanned vertical movement or ejection. This type of event could be the natural consequence of energetic phenomena which could occur - or even intentionally be initiated within a system, depending on the objectives of an experiment being conducted with the system.

170. See footnote 168 below. 
hazards also determine design basis situations for components, often called load cases, where the general objective for hazards is to ensure that they do not prevent fundamental safety functions from being performed, despite their direct and indirect effects.

Therefore, like the pressurised water reactors in the nuclear power reactor fleet, the "load case" approach has been supplemented (for safety reviews and new research reactor projects) by the implementation of an "event-level earthquake" approach, which takes into account the fact that an earthquake can be the cause of other internal hazards due to the failure of components not designed for earthquakes. It should be noted that in principle, this type of approach can be applied to other hazards besides earthquakes. The approach is used to:

- identity components not specifically designed for earthquakes;

- study the impacts should they fail in the event of an earthquake in order to determine whether they can jeopardise the functional requirements of components designed for earthquakes and that perform fundamental safety functions;

- if this is the case, decide on any measures to be taken: reinforce components not designed for earthquakes, protect major components that could be affected.

It is assumed that an earthquake will cause the loss of off-site power supplies ${ }^{171}$ (loss of off-site power).

Just as for power reactors from the nuclear power reactor fleet, an additional category of operating conditions corresponding to multiple failures or accumulated events (which can be highly unlikely) is now taken into account for the design and safety demonstration of research reactors. An example of this is a station blackout ${ }^{172}$, or a seismic margin earthquake ${ }^{173}$ while a heavy load is being lifted in the reactor building, with the requirement that the load not be dropped. For this, the designer of the Jules Horowitz Reactor uses the expression risk limitation conditions (RLC), which include controlled severe accidents (CSA) under the $4^{\text {th }}$ level of defence in depth.

Finally, just as for reactors in the nuclear power reactor fleet, particular attention must be paid to events excluded from the list of operating conditions. These events are not covered by specific measures to limit their consequences (as they may be unachievable). Their exclusion must therefore be justified by proving that their occurrence is physically impossible or highly unlikely with a high level of certainty. In the latter case, a case-by-case analysis should be performed, as a generic probability threshold does not appear to be relevant ${ }^{174}$. Preventing "excluded" events requires stronger design, construction and in-service inspection measures compared to those adopted to prevent events whose occurrence has not been excluded.

171. LOOP: Loss Of Off-site Power.

172. Combination of loss of off-site power and main emergency diesel generators (SBO: station blackout).

173. See section 7.4.2.

174. See the "technical directives for the design and construction of next-generation pressurised water reactors", established by the GPR with German experts in October 2000 and used for the EPR reactor project. 
The abovementioned approach is gradually being applied to old research reactors during their safety reviews. Besides the case of the CABRI reactor mentioned above, this includes the ORPHEE reactor at Saclay, and the RHF.

Some of the events studied for research reactors are therefore similar to those adopted for reactors from the nuclear power reactor fleet, such as a breach or even complete failure of a reactor coolant main pipe, the inadvertent removal of an absorber component from the core area, or partial or complete loss of electrical power. Some other events are specific to research reactors given the experiments that are conducted in them or planned.

Safety analyses and assessments carried out by IRSN as part of work to upgrade the $C A B R I$ reactor, which included the installation of a pressurised water loop to replace the sodium loop, led to the adoption of rules and practices used for pressurised water reactors - the loop, related systems, its containment tank constituting the coolant circuit, related systems and the containment building of a PWR. The following are examples of some of these aspects:

- while the operating conditions associated with the reactor itself were defined by drawing heavily on events adopted for pool-type research reactors, the operating conditions associated with the loop were naturally drawn from the operating conditions adopted for pressurised water reactors;

- the water loop containment tank was designed to withstand a "design pressure" equivalent to the pressure attained in the event of break of the loop (equivalent to the primary coolant main pipe in a PWR), corresponding to the loss of coolant accident (LOCA) studied for this type of reactor ${ }^{175}$. The recommendations for metal containment vessels in the ASME design and construction code, which is widely used across the world for light water reactors, were used as a point of reference in this area;

- the risk of complete failure of the part of the loop in the reactor ("in-reactor cell") which could have severe consequences on the driver core (sudden depressurisation of the loop water which could compact assemblies in the driver core and prevent absorber rods from dropping) should be made sufficiently unlikely. The safety valves on the loop's coolant system obviously help prevent such an event. However, they needed to comply with regulations for safety components (valves) for pressure devices;

- the pressurised water loop complies with requirements contained in the regulations for pressurised devices ("ESPN" Order).

These cases of combined use of the rules and practices used for research reactors and pressurised water reactors did not create any problems, which suggests good consistency and compatibility between the approaches.

175. This involves a complete double-ended guillotine break of the loop inside the tank containment of the loop (figure 5.17) (i.e. 2A, where A refers to the cross-sectional flow area of the coolant in the system), combined with a compressed air pipe break, which could be caused by the first break. 
As stated above, in some cases, probabilistic safety assessments can provide useful insight along with the deterministic approach for new projects, major modifications or safety reviews of research reactors ${ }^{176}$. For example, targeted probabilistic assessments can help guide design decisions. A probabilistic assessment of potential residual heat removal failures can be used to choose design options for the general architecture of cooling systems, redundancy and equipment diversification. Probabilistic safety assessments can also be used to confirm or modify the safety classification of components. Furthermore, if probabilistic safety assessment models are not available, a simplified "lines of defence" approach ${ }^{177}$ can also provide useful insight, as was the case in the early 2000s with the safety review of the high-flux reactor in Grenoble.

\subsubsection{Reference accidents}

As stated earlier, when the first research reactors were being designed around fifty years ago, potential incidents and accidents were taken into account. Incidents and accidents began being studied, especially what are referred to in France as "reference accidents". These accidents were considered as worst-case scenarios and used to assess the acceptable nature of technical and organisational provisions adopted to ensure the safety of the facility in question.

These reference accidents were defined taking into account the specific features of reactors and generally considering the failure of several systems or human errors, which would or could potentially damage fuel elements or the reactor core.

For water-cooled research reactors that use uranium- and aluminium-based fuel (with aluminium cladding), the BORAX-type accident, named after the American facility where tests for this type of accident were conducted, was adopted in France. This type of accident is representative of the risks involved with a sudden insertion of high reactivity into the core, i.e. partial or complete core meltdown potentially followed by a steam explosion in the pool.

Reactivity insertion causes a runaway chain reaction that can be limited by the effects it produces as increased fuel and water temperatures have a negative effect on reactivity (neutron feedback). However, if the reactivity insertion is too quick or substantial, the neutron feedback is not enough to prevent damage to the fuel. In the case of the BORAX-type accident, which concerns reactors that use uranium- and aluminium-based fuel, fuel and cladding quickly reach their melting temperature $\left(660^{\circ} \mathrm{C}^{178}\right)$. The fuel can then disperse in the water, which remains relatively cool given

176. See section 3.4.3. In 2010, IRSN conducted a feasibility study for a Level 1 PSA for the Jules Horowitz Reactor. See the presentation made at the PSAM 2010 conference: "10th International Probabilistic Safety Assessment, Feasibility study to develop a PSA for the Jules Horowitz research reactor", Laborde A., Georgescu G., Cochemé F., Lanore J.-M.

177. This approach was presented by M. Lavérie (head of the SCSIN from 1986 to 1993) at a conference held in 1982 in Lyon on liquid metal cooled fast neutron reactors (see Proceedings of the LMFBR Safety Topical Meeting, Lyon (1982), p.l-335.

178. This value corresponds to the melting temperature of aluminium. 
the kinetics of the accident, and cause a steam explosion due to the sudden transfer of energy from the melted substances to the water.

Due to the destructive impacts of such an accident, the initial focus is to prevent the failures that could cause it. However, the accident could still potentially occur. As its kinetics are too rapid for an emergency shutdown to be sufficiently effective, measures are taken to limit its consequences. These measures are mainly based on the ability of the pool to resist a potential steam explosion and maintain the melted core under water (as the water provides cooling and a biological shield), and the ability of the reactor building to withstand the accident and contain the radioactive substances released in the building. Outside France, this type of accident has not been fully taken into account (fuel-water interaction) for the design of pool-type research reactors with a uranium and aluminium alloy-based fuel, except for the BR2 reactor at the Mol centre in Belgium.

For the OSIRIS, ORPHEE and RHF, an "in-air" melt accident involving a fuel element being handled in the reactor (caused by failures during handling) was also adopted. Unlike an underwater core melt accident such as the BORAX-type accident, an "in-air" melt accident causes more radionuclides to be released in the reactor building as there is no water to trap the fission products. The possibility of "in-air" core meltdown began being taken into account when the RHF was being designed.

Chapter 8 will cover reference accidents adopted for French research reactors and the BORAX-type accident in particular.

\subsubsection{Application of general safety objectives}

The general safety objectives were expressed qualitatively in section 7.1. However, just as with nuclear power reactors, the designers and operators of research reactors can adopt general safety objectives expressed quantitatively in terms of "acceptable" radiological consequences for humans and the environment, in the form of "reference values" for doses, different categories of operating conditions and the conditions of the complementary domain (BDBA or DEC). Although this is useful for structuring basic designs and assessing the choices made at this stage, in line with the Farmer diagram (figure 7.1), these "reference values" can under no circumstances be considered as acceptability criteria, as the radiological consequences must always be limited as far as reasonably possible while taking into account economic and social factors (optimisation principle).

Safety is above all assessed by applying the defence in depth principle and not just comparing the radiological consequences of pre-established values. In particular, calculating the individual radiological consequences would not reflect their severity, which depends on the number of people affected (which can be high for research reactors located in highly urbanised areas) and the degree and duration of contamination resulting from an accident.

In addition, designers and operators can apply the general safety objectives as "relay" criteria or "decoupling" criteria used to study operating conditions and determine whether measures to limit their consequences are sufficient (percentage of fuel element cladding failures, percentage of molten fuel, etc.). 


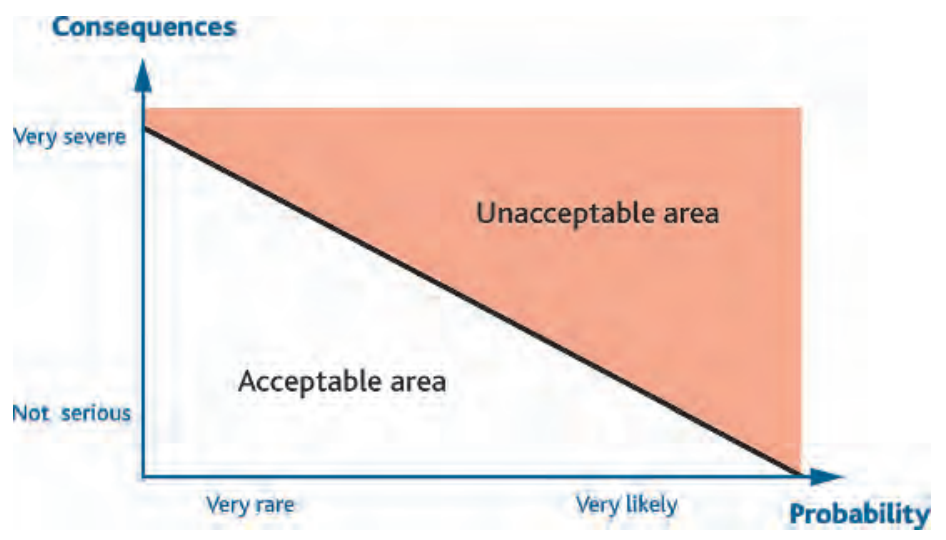

Figure 7.1. Farmer diagram showing the relationship between probability and consequences.

\subsubsection{The graded approach in France}

The Order of 7 February 2012 establishes the general rules for the design, construction, operation, permanent shutdown, dismantling, maintenance and monitoring of basic nuclear facilities. It states that "Their application is based on an approach that is proportional to the extent of the risks or drawbacks inherent to the installation". The Order particularly underscores the "proportional approach" for the number and effectiveness of confinement barriers (especially for the design of research reactors, as the number of barriers can vary from one reactor to the next), the qualification of the facility's major components, the frequency of emergency exercises or the monitoring of external service providers.

The use of a deterministic approach that defines and studies operating conditions from internal initiating events, internal hazards (linked to the reactor itself) and external hazards (linked to the reactor site) for the design, safety demonstration or safety reviews of research reactors automatically leads to safety measures that are adapted to the research reactor in question and its site, and proportional to their risks.

It should also be noted that the safety classification of equipment within the same nuclear facility means that a number of their requirements are proportioned to their importance to safety (safety coefficients for their design, types of welding authorised by design and construction codes, scope and nature of completion inspections, inservice inspections, etc.).

\subsection{Specific safety features of research reactors}

\subsubsection{Power densities, fuel and core neutron characteristics}

Despite having much lower overall power, the power densities generated by research reactors are often higher than for power reactors, given the size of their core, 
Table 7.1. Operating conditions: categories and examples for a pool-type reactor.

\begin{tabular}{|c|c|c|}
\hline $\begin{array}{l}\text { Categories of } \\
\text { operating } \\
\text { conditions }\end{array}$ & $\begin{array}{l}\text { Order of magnitude for } \\
\text { the annual frequency } \\
\text { per reactor (and upper threshold } \\
\text { expressed as a probability) }\end{array}$ & $\begin{array}{l}\text { Examples of operating conditions for a } \\
\text { pool-type reactor, with neutron channels } \\
\text { (indicated by }{ }^{*} \text { ), using heavy water } \\
\text { (indicated by }{ }^{* *} \text { ) - Excluding events to be } \\
\text { taken into account for fuel transfer casks } \\
\text { (loss of cooling, etc.) }\end{array}$ \\
\hline $\begin{array}{l}\text { CATEGORY } 1 \\
\text { Normal operating } \\
\text { conditions }\end{array}$ & $\begin{array}{l}\text { Number of occurrences defined } \\
\text { according to the operating } \\
\text { programme } \\
(P=1)\end{array}$ & $\begin{array}{l}\text { - Stable states and normal transient } \\
\text { conditions (including irradiation } \\
\text { experiments) }\end{array}$ \\
\hline $\begin{array}{l}\text { CATEGORY } 2 \\
\text { Minor yet frequent } \\
\text { incidents }\end{array}$ & $\begin{array}{l}\text { Up to several occurrences } \\
\text { per year } \\
(P<1)\end{array}$ & $\begin{array}{l}\text { - Loss of fuel cladding leaktightness } \\
\text { - Coolant leak or break of small } \\
\text { equivalent diameter (e.g. } \Phi<10 \mathrm{~mm}) \\
\text { - Partial loss of coolant flow } \\
\text { - Total loss of secondary coolant } \\
\text { system flow } \\
\text { - Leak affecting a heat exchanger } \\
\text { between light water and heavy } \\
\text { water }(* *) \\
\text { - Coolant pump shutdown during } \\
\text { shutdown } \\
\text { - Loss of integrity of a thimble casing } \\
\text { resulting in heavy water entering the } \\
\text { thimble }(*)(* *) \\
\text { - Leak or break affecting effluent } \\
\text { discharge systems } \\
\text { - Short-term loss of offsite } \\
\text { electrical supply (e.g. < } 1 \text { hour) } \\
\text { - .. }\end{array}$ \\
\hline $\begin{array}{l}\text { CATEGORY } 3 \\
\text { Unlikely accidents }\end{array}$ & $\begin{array}{c}<10^{-2} \\
\left(P<10^{-2}\right)\end{array}$ & $\begin{array}{l}\text { - Inadvertent removal or withdrawal of an } \\
\text { absorber element (possible in Cat. } 2 \text { ) } \\
\text { - Coolant break of "intermediate" } \\
\text { equivalent diameter } \\
\text { (e.g. } 10 \mathrm{~mm} \leq \Phi<100 \mathrm{~mm}) \\
\text { - Break of a standard aluminium thimble } \\
(*) \\
\text { - Failure of a heavy water sleeve }\left(^{* *}\right) \\
\text { - Clogging of a core fuel element } \\
\text { cooling channel } \\
\text { - Clogging of several channels of a fuel } \\
\text { element in a storage area } \\
\text { - Dropped transport cask containing fuel } \\
\text { elements in the facility } \\
\text { - ... }\end{array}$ \\
\hline
\end{tabular}


Table 7.1. (Continued)

\begin{tabular}{|c|c|c|}
\hline $\begin{array}{l}\text { CATEGORY } 4 \\
\text { Major yet } \\
\text { hypothetical } \\
\text { accidents }\end{array}$ & $\begin{array}{c}<10^{-4} \\
\left(P<10^{-4}\right)\end{array}$ & $\begin{array}{l}\text { - Absorber ejection (potentially causing core meltdown) } \\
\text { - possibly studied as an additional operating condition } \\
\text { if multiple failures are involved } \\
\text { - In-pool reactor block failure (causing reciprocal } \\
\text { transfers between light water and heavy water) }\left(^{(*}\right) \\
\text { - Coolant break of large equivalent diameter } \\
\text { (e.g. } \Phi \geq 100 \mathrm{~mm} \text { ) } \\
\text { - Break of a zirconium alloy thimble } \\
\text { - Core coolant bypass' }{ }^{179} \text { (potentially causing core meltdown) } \\
\text { - In-pool double-ended guillotine break of a water } \\
\text { inlet collector }{ }^{180} \text { in the core }{ }^{181} \\
\text { - In the hot cell, accidental cutout of a fuel element } \\
\text { - ... }\end{array}$ \\
\hline $\begin{array}{l}\text { Beyond design- } \\
\text { basis area }\end{array}$ & $\begin{array}{l}<10^{-6}, 10^{-7} \\
\text { per family }\end{array}$ & $\begin{array}{l}\text { Additional operating conditions (some may cause melting in } \\
\text { the core or core meltdown under water or in the air in the } \\
\text { event of fuel element uncovery) } \\
\text { - Inadvertent removal of an absorber with failure of } \\
\text { the reactor protection system } \\
\text { - Failure of the main heavy water system with failure of } \\
\text { the vacuum relief valve }\left(^{*}\right) \\
\text { - Loss of secondary coolant system flow with failure of } \\
\text { the protection system } \\
\text { - Total failure of a thimble with isolation failure } \\
\text { ("window" and safety valve or upstream and downstream } \\
\text { safety valves'182) }(* *) \\
\text { - Complete loss of offsite and back-up electrical power supply } \\
\text { - Loss of offsite electrical power supply and failure } \\
\text { of the reactor protection system } \\
\text { - BORAX-type accident (reactivity accident) } \\
\text { - Loss of entire reactor water inventory (heavy and } \\
\text { light water) }(* *) \\
\text { - ... }\end{array}$ \\
\hline & & $\begin{array}{l}\text { Other accidents studied or excluded by prevention } \\
\text { measures } \\
\text { - Uncovery of stored fuel elements } \\
\text { - Failure of the two "heat source" or "heat sink" vessels }\left(^{*}\right) \\
\text { - Explosion of a "cold source" thimble, causing } \\
\text { internal damage to the reactor block }\left(^{*}\right) \\
\text { - Core meltdown with total containment failure } \\
\text { - ... }\end{array}$ \\
\hline
\end{tabular}

179. For example, in the case of the RHF, a break in the "stack", located above the core tank.

180. Case of the RHF: see figure 5.12.

181. In the case of the RHF, this would result in light water entering the fuel assembly in the core (instead of heavy water).

182. See the description of these components in section 7.3.2. 
Table 7.2. Core power densities and coolant temperatures for different types of reactors.

\begin{tabular}{|l|c|c|l|l|c|}
\hline & $\begin{array}{c}\text { Pressurised } \\
\text { water reactor }\end{array}$ & $\begin{array}{c}\text { Sodium-cooled } \\
\text { fast neutron } \\
\text { reactor }\end{array}$ & OSIRIS & RHF & JHR \\
\hline $\begin{array}{l}\text { Power } \\
\text { density } \\
\text { in } k W / l\end{array}$ & $\sim 100$ & $\sim 300$ & $\sim 300$ & $\sim 1,200$ & $\sim 600$ \\
\hline $\begin{array}{l}\text { Coolant temperature } \\
\text { at core inlet and } \\
\text { outlet in }{ }^{\circ} \mathrm{C}\end{array}$ & $286-323^{(*)}$ & $350-550$ & $38-48$ & $30-48$ & $25-36$ \\
\hline
\end{tabular}

${ }^{(*)}$ These values are for Bugey 900 MWe PWRs.

in order to obtain the neutron fluxes required for experiments or irradiation ${ }^{183}$. Table 7.2 shows several power densities in the cores of different types of reactors, including power reactors.

The power density generated depends on the type of fuel used. It can be high with fuel that is highly enriched in fissile uranium-235. Several types of fuel are used in research reactors, depending on their use. For critical assemblies where flexible use is essential, operators generally have a broad inventory of fuel elements in the form of rodlets or platelets, allowing them to create cores "à la carte". For this type of reactor, core assemblies are created manually in the installation itself.

For irradiation reactors and "neutron beam outside" reactors, whose main purpose is to produce strong neutron fluxes, it is essential for fuel assemblies to be properly cooled when the reactor is in operation. Fuel elements are designed to meet this purpose. For example, the use of curved plates (figure 7.2) provides greater stiffness and ensures that the desired spacing is maintained between the plates in various degraded or hazard conditions (earthquake, etc.).

As stated in chapter 2, as part of international efforts to prevent nuclear weapons proliferation, procurement of highly enriched with uranium-235 fuels can be a problem. A number of research reactors have therefore converted to the use of silicide fuel, using a $\mathrm{U}_{3} \mathrm{Si}_{2}$ formula alloy that reduces uranium-235 enrichment to less than $20 \%$ while maintaining the potential and capacities of these reactors. However, this "conversion" can raise problems for some research reactors due to dimensional and other constraints, making it difficult to make changes, especially in their cores. To

183. Research reactor designs must achieve the best compromise between several contradicting requirements. This includes designing a small core to achieve high fission densities, creating a sufficient experimental volume to install all experimental devices, extract high power densities without negatively affecting the neutron performance of the core or hinder its experimental use ("Les réacteurs de recherche", Francis Merchie, L'Encyclopédie de l'énergie, 2015). 


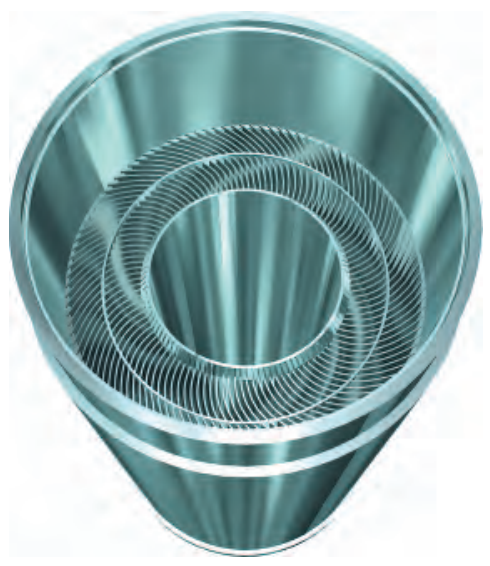

Figure 7.2. Curved plate fuel element used in the FRM-II reactor in Garching, Germany. () FRMII Technical University of Munich.

compensate for the loss of uranium-235 enrichment, new higher density uranium alloys ${ }^{184}$ are being studied, but these would come with other drawbacks (more frequent replacement of core fuel, less efficient neutron absorbers, etc.). This issue is still being explored and is at the heart of the question around choosing the type of fuel for the Jules Horowitz Reactor ${ }^{185}$. Research is being carried out to develop and qualify other types of fuel. The CEA and other organisations ${ }^{186}$ are studying fuel made of $20 \%$ enriched uranium-235 and molybdenum grains with aluminium alloy cladding (currently called UMo).

Aluminium (or aluminium alloys such as AG3NET or zirconium) is widely used in research reactors for fuel, fuel cladding, internal structures and components (such as neutron channels). To achieve a good thermodynamic yield, nuclear power plants operate at the highest possible temperatures, whereas apart from a few exceptions, research reactors are "cold" reactors. This allows for the use of these types of materials, which have much better neutron characteristics than steel (neutron transparency), although they may have poorer mechanical properties depending on their composition and treatment (in terms of yield strength, rupture elongation, etc.).

In terms of neutronics ${ }^{187}$, the thermal neutron fluxes that can be used for experimental programmes must achieve values of $1.10^{13}$ to over $1.10^{15}$ neutrons. $\mathrm{cm}^{-2} \cdot \mathrm{s}^{-1}$. The neutron flux in a reactor is made up of fast neutrons resulting directly from fission, thermal neutrons after slow-down in the moderator, and intermediate neutrons in the

184. NUREG-1313 silicide has a density of $4.8 \mathrm{gU} / \mathrm{cm}^{3}$. With new fuel, the aim is to achieve a density that is approximately twice higher.

185. "Les combustibles nucléaires", Monograph by the CEA Nuclear Energy Division, 2008.

186. The United States (ANL), Canada, Russia, South Korea and Argentina are contributing to the qualification of this new fuel. Experiments have been conducted in the OSIRIS reactor, and the HFR and BR2 reactors are also being used.

187. "Les réacteurs de recherche", Francis Merchie, L'Encyclopédie de l'énergie, 2015. 
Table 7.3. Neutron parameters for the cores of different types of reactors.

\begin{tabular}{|l|c|c|c|c|c|}
\hline & $\begin{array}{c}\text { Pressurised } \\
\text { water reactor }\end{array}$ & $\begin{array}{c}\text { Sodium-cooled } \\
\text { fast neutron } \\
\text { reactor } \\
\text { PHENIX }(*)\end{array}$ & OSIRIS & RHF & JHR \\
\hline $\begin{array}{l}\text { Maximum flux in } \\
\text { neutrons.cm }{ }^{-2} . \mathrm{s}^{-1}\end{array}$ & 1 to $3.10^{13}$ & $4.510^{15}$ & $5.410^{14}$ & $1.910^{15}(* *)$ & $1.110^{15}$ \\
\hline Doppler effect & $-3 \mathrm{pcm} /{ }^{\circ} \mathrm{C}$ & $-0.6 \mathrm{pcm} /{ }^{\circ} \mathrm{C}$ & $-3 \mathrm{pcm} /{ }^{\circ} \mathrm{C}$ & & $-2.5 \mathrm{pcm} /{ }^{\circ} \mathrm{C}$ \\
\cline { 1 - 4 } $\begin{array}{l}\text { Moderator } \\
\text { effect }\end{array}$ & $\begin{array}{c}\text { from }-10 \text { to } \\
-60 \mathrm{pcm} /{ }^{\circ} \mathrm{C}\end{array}$ & $\begin{array}{c}\text { generally } \\
-0.06 \mathrm{pcm} /{ }^{\circ} \mathrm{C} \\
\text { but positive in } \\
\text { some areas of } \\
\text { the core }\end{array}$ & $-14 \mathrm{pcm} /{ }^{\circ} \mathrm{C}$ & $\begin{array}{c}-17 \mathrm{pcm} /{ }^{\circ} \mathrm{C} \\
\text { (including }\end{array}$ & $-20 \mathrm{pcm} /{ }^{\circ} \mathrm{C}$ \\
\cline { 1 - 4 } $\begin{array}{l}\text { Effective beta } \\
\text { (delayed } \\
\text { neutron } \\
\text { fraction) }\end{array}$ & $\begin{array}{r}300 \mathrm{pcm} \\
\text { Dopler effect) }\end{array}$ & $731 \mathrm{pcm}$ & $713 \mathrm{pcm}$ & $730 \mathrm{pcm}$ \\
\hline
\end{tabular}

${ }^{(*)}$ The values given are for the PHENIX reactor operating at a maximum power of $350 \mathrm{MWth}$ (power adopted for its operation from 2003 to 2010).

${ }^{(* *)}$ This corresponds to the sum of $1.510^{15}$ neutrons. $\mathrm{cm}^{-2} \cdot \mathrm{s}^{-1}$ of thermal neutrons available in the end of thimbles, and $3.510^{14}$ neutrons. $\mathrm{cm}^{-2} \cdot \mathrm{s}^{-1}$ of fast neutrons in the core fuel element.

process of slowing down (slowing occurs via successive collision of neutrons against the nuclei of moderator atoms). Depending on whether the reactor is well-moderated or under-moderated, the neutron spectrum will have a more or less fast component, which could be detrimental or desired, depending on the objectives of experimental programmes.

Furthermore, the spatial distribution of neutrons is not uniform and decreases from the centre to the core perimeter, with localised disturbances due to things such as the movement of control absorbers and the presence of experimental devices. This causes variable distribution of the residual heat over time and space and therefore the presence of "hot spots" that need to be well-anticipated and managed from a thermal hydraulic standpoint in order to prevent fuel from overheating beyond set limits and being damaged. This safety concern will be covered in section 10.1.1, with the discovery in 2004 of several melted fuel rods in the CABRI reactor driver core.

\subsubsection{Usage rates}

Another feature of research reactors is the specific ways they are used. Irradiation reactors or "neutron beams outside" reactors operate in cycles. During a cycle, they are generally in steady-state operation 24 hours a day. At the end of a cycle, they are shut down for refuelling. In this way, such reactors can provide a stable supply of neutrons (beams for experiments) and over a significant period of time (irradiation). 
The operating programmes for critical assemblies vary significantly and are closely linked to the test programmes performed, which may last from a few months to several years. Such test programmes start with construction of the experimental core, which may take several months. The test phase proper then follows, when the reactor may operate for just a few hours a day, or throughout the day. However, it is usually shut down every night. This phase may also involve changes to the core configuration, in order to meet testing needs.

For reactors used for specifically safety-related tests, preparation times for tests or series of tests may be fairly long. One example of this is the test loop on the CABRI reactor, which has required several years of work to change. The time between two tests may also be long, for example because special provisions are required to handle a degraded test fuel element. The actual test period can, however, be very short in comparison with the preparation periods and the times between tests.

\subsubsection{Organisational and human factors}

One aspect of research reactors, compared with other nuclear facilities such as nuclear power reactors, is the particular involvement of people in reactor operation and the use of reactors for research. People do perform a range of operations in most nuclear facilities, such as process management, refuelling, maintenance, monitoring, but with research reactors people may often have to handle fuel elements using handling poles or put together the fuel elements (this is the case, for example, for some critical assemblies).

In addition, the large amount of handling of experimental devices placed in or near the reactor core is to be noted.

Moreover, in many research reactors, there are two different groups of workers whose actions have an impact on safety: the reactor operating teams who are responsible for running the reactor within safe limits, and the scientists that use the experimental devices in order to generate research outputs. The latter group may not be so conscious of the safety limits and reasons for such rules. The authority of the facility manager over both groups of workers is therefore essential.

Furthermore, after a test campaign, many human operations may be necessary, such as disassembling or reassembling systems in preparation for the next experiments, or cleaning components. The potential safety and radiological protection consequences of such operations must be clearly understood.

Finally, research reactor activities very often are evolving and discontinuous over time. Activities can change, depending on the planned research programmes, and even the slightest consequences of such changes must be considered in terms of safety and radiological protection. Moreover, whenever major changes occur, involving longerterm stoppage of some activities in order to undertake equipment modifications, the effect of such stoppages on staff skills must be assessed. 
Risk assessments relating to human activities in research reactors can draw on a specific approach ${ }^{188}$ which involves:

- determining which activities are "safety-sensitive", meaning activities which could have significant safety consequences if incorrectly performed;

- identifying what provisions are in place to ensure such activities can be performed reliably;

- assessing the effectiveness of those provisions.

The sensitivity of any given activity can be assessed on the basis of a range of factors: potential consequences of incorrect performance, complexity of the tasks, repetitive nature of the operation, number of workers involved, coordination requirements, etc.

To illustrate the point, two activities in French research reactors can be mentioned that are deemed to be particularly sensitive:

- for the MASURCA model, the fabrication of "à la carte" fuel elements from rodlets or platelets in the storage warehouse (criticality risk in the event of error);

- for the ISIS reactor used for successive training sessions, the setting of safety thresholds (risk of inadequate reactor protection in the event of an unexpected transient).

In general, the experiments may require reconfiguration of the protection system, and such adjustments must be made in a reliable and traceable way.

Although facility operators have identified the vast majority of activities which could have significant safety consequences in the event of error, other activities that may have less obvious safety effects or which are sensitive chiefly due to the complexity of the operations to be performed may require further analysis.

As mentioned above, any needs for coordination between different teams are usually included in the aspects considered when assessing whether a given activity is sensitive. This is the case, for instance, for experiments that require preparation and especially close coordination between the operating personnel and the scientific researchers. Thus, the tests undertaken under the Phebus FP programme (see focus at end of chapter 5) required in-depth preparation to mitigate any risks of conflict of interest: the instruments used included redundant and diversified measurement devices and the test procedures specified various predetermined shutdown thresholds. The goal was to avoid stopping the tests too early, given the test objectives, but still to ensure the reactor would be shut down and containment maintained if there was any risk of excessive damage to the "barriers" between the test fuel and the driver core. Test procedures were developed for the operators, to specify in particular whether or not tests should be continued, based on the instrumentation status (whether the temperature measurement devices were in service, failed or saturated,

188. "Contrôle" Journal no. 176 of July 2007: "Les facteurs organisationnels et humains et la sûreté des réacteurs d'expérimentation", F. Jeffroy and M.-L. Delaporte-Normier, IRSN, P 47. 
etc.) and on predetermined limits. These provisions were submitted to the French Nuclear Safety Authority (ASN).

\subsection{Features of research reactors by main safety function}

This section presents the main technical features of research reactor that are important for safety.

\subsubsection{Controlling core reactivity}

Core reactivity (annotated $\rho$ and expressed in pcm - per cent mille) is a parameter used to represent the neutron population (number of neutrons) in a core and its variation over time. When the population is stable, the reactor is said to be "just critical" and reactivity is zero $(\rho=0)$. This population results from the neutrons generated by fission reactions, neutrons emitted later by some fission products (so-called "delayed neutrons") and neutrons that leak out or are captured (e.g. in absorbent materials). Operators control the reactivity in a reactor core by using neutron-absorbing materials (also known as "neutron poisons") such as boron, cadmium and hafnium. These materials are used in control absorbers (or safety absorbers in research reactors). These are mobile components inserted into the reactor core to enable its reactivity to be adjusted and controlled. Vertical absorber movements are controlled by mechanisms that are usually found above the core. However, in some cases, to facilitate access to experimental or irradiation devices, absorber motion may be controlled by mechanisms in the bottom of the reactor block. This is true of the OSIRIS and Jules Horowitz reactors, which have a room under the reactor pool that houses these mechanisms. This means that the potential risks of water leakage - possibly involving contaminated water in the event of a reactor accident - into reactor basements need to be managed by installing waterproof coatings in the control mechanism rooms.

Some absorbers are used for reactor control (control absorbers) and others are used for reactor scram (safety absorbers). To shut the reactor down, all absorbers are fully inserted into the reactor, thus bringing it to sub-criticality $(\rho<0)$, with an adequate deficit reactivity margin (or shutdown margin). Once the reactor has been shut down, safety reasons may require some safety absorbers (one or two) to be withdrawn from the core zone, in order to maintain an appropriate negative reactivity level in case of handling errors, for instance during core operations such as refuelling. When the reactor starts up, operators first withdraw the safety absorbers from the core, maintaining it in a sub-critical state ${ }^{189}$, and then the control absorber(s) is (or are) gradually withdrawn from the core until it reaches criticality $(\rho=0)$. This absorber (or these absorbers) are then used to increase or decrease reactor power and to compensate for fuel burn-up when the reactor is in operation. The safety absorbers are generally held axially outside

189. This is a design requirement for the core and absorbers. 
the zone of the core ${ }^{190}$ (usually by means of electromagnets). In incident or accident conditions, the electromagnets are disabled, and the absorbers drop or are rapidly inserted (with a pressurized gas device) into the core or core zone to cause automatic reactor shutdown (see figure 7.3).

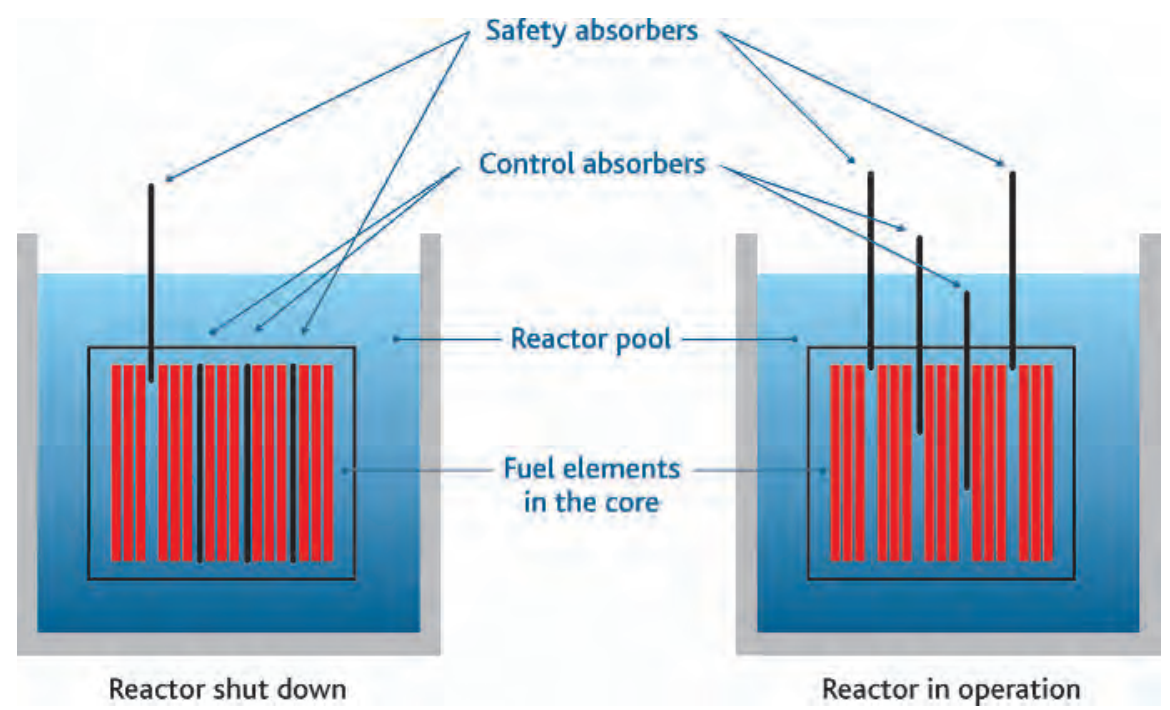

Figure 7.3. Position of the safety absorbers and control absorbers in a pool-type reactor in shutdown conditions (left) and in operation (right). (c Georges Goué/IRSN.

Each reactor has a protection system connected to various redundant sensors (temperature, pressure, neutron flux, etc.) and actuators. The signals emitted by the sensors are processed using an appropriate and safe "voting" logic. The monitored parameters and the threshold values that trigger safety actions (chiefly a safety absorber drop) are specific to each reactor. The threshold values are determined by "operating conditions ${ }^{191 " ~ s t u d i e s . ~ A ~ s a f e t y ~ a b s o r b e r ~ d r o p ~ m a y ~ a l s o ~ b e ~ t r i g g e r e d ~ b y ~ s i g n a l s ~ f r o m ~ o u t s i d e ~}$ the reactor (e.g. earthquake, impact on the reactor building, loss of required negative pressure in a room) or by signals from sensors that monitor certain operating parameters relating to the experimental devices, when this is deemed necessary for reactor safety.

The protection system is a key element in research reactor safety. Various options are used in design, in order to ensure a high level of protection system reliability, including redundancy, technological diversification and the physical separation of measurement pathways. A single failure criterion is used to check that no single failure can

190. The safety absorbers may indeed be outside, but close to the core, as is the case with the RHF, for example.

191. Conservative margins are added to the operating conditions in order to take into account uncertainties, for example with the measured reactor values or the time required to activate protective systems. 
prevent a system from performing its allocated safety function. This can be achieved by redundancy, which means that system elements are duplicated (or more) and distributed across different "channels" or "trains" to ensure that each path can perform the system function. In addition to redundancy, the "trains" can be separated from one another geographically, to ensure that no hazard, such as a fire, can affect all trains at the same time (referred to as a common mode failure). Diversification means using, as far as necessary, different designs or technologies for the components on the redundant trains of a given system, to ensure that the system is sufficiently reliable. Furthermore, design of important "active" components should be "fail safe", meaning that any component failure should switch it to a state that is favourable for safety. For instance, a "safe" position for the absorbers would be full insertion into the reactor core. The absorbers control system is designed with electromagnets that drop them into the core (for mechanisms located above the fuel zone) if electrical power is lost.

Core loading is an important operation, involving loading the fuel elements into the core, and is performed under procedures that require many checks and controls. Hardware design provisions can be used to physically prevent positioning errors that could jeopardize reactor safety.

During periodical safety reviews, in addition to the protection system described above, some research reactors have had a back-up system added to stop the chain reaction in some accident conditions under which core deformation could prevent or dangerously delay absorber insertion (e.g. in the event of a major earthquake). This may be as simple as a system to inject a neutron absorber in aqueous solution into the reactor coolant. This type of system has for instance been implemented on the CABRI reactor (borated water injection) and has been adopted as a core melt accident management provision on the Jules Horowitz reactor.

As well as the conventional reactivity control strategies described above, it is also important to prevent failures that could lead to reactivity insertions in a core.

From research reactor design phase, study is therefore required into any absorber mechanism malfunction that could lead to absorber withdrawal or ejection from the core zone (generating a reactivity insertion) instead of insertion into the core or core zone to control reactivity. Design provisions can be implemented to restrict the amplitude or rate of absorber withdrawal, as has been the case for the Jules Horowitz reactor.

Likewise, specific leakage scenarios or reactor block structure failures (reactor vessel, thimbles of neutron beams, etc.) that could lead to reactivity insertion into a core (e.g. for the RHF, ingress of light water into the heavy water flowing in the core) require analysis and appropriate in-service monitoring of the relevant structures in order to ensure their occurrence is sufficiently unlikely.

\subsubsection{Cooling the reactor}

This safety function is not particularly problematic for very low power reactors, up to approximately $100 \mathrm{~kW}$, in which the heat naturally dissipates through reactor structures. For higher power reactors, it is obviously essential to have enough coolant, and the core can be cooled either by the natural upward flow of this coolant in the 
reactor core (natural convection), or by a stronger flow of coolant which requires forced convection. In the latter case, the reactor core is cooled via a reactor coolant system, which uses circulator pumps to generate the coolant flow. This reactor coolant system is itself cooled by a secondary cooling system, in order to prevent radioactive releases, since the reactor coolant can potentially be contaminated.

The reactor coolant system may be an entirely closed circuit, or may be partially open to the reactor pool. Coolant system failures (loss of flow, pressure loss, loss of coolant) are detected by the protection system, which can trigger alarms or even shut down the reactor automatically. Residual heat still needs to be removed, and the level of this will depend on previous reactor operating regimes, in particular its operating power. For reactors that operate at a power of a few megawatts, natural convection may provide sufficient flow to cool the fuel in the reactor after shutdown. However, in order to start this flow, water from the pool in which the core is submerged must be able to get into the fuel elements. Valves in the core coolant pipes, at the entrance to the core, ensure that this connection can be made between the reactor coolant system and water from the pool. When the reactor is operating at power, these valves are kept closed by the pressure differential between the water in the pool and the reactor coolant system. They open naturally when the pressure differential reduces (e.g. loss of reactor coolant flow). These valves are generally duplicated to prevent any loss of this connection between the pool and the reactor coolant system in the event of a valve failure. (This is an application of the single failure criterion). Depending on the residual power released by the reactor core, it may also be necessary, in the first few minutes after reactor shutdown to maintain a higher coolant flow rate than the natural convection rate. The reactor coolant pumps therefore have flywheels, which slow them down gradually, to maintain sufficient reactor coolant flow in the reactor core for some time after shutdown. The valves and flywheels mentioned above are components that need no external supply of electricity, compressed air or other utilities to operate.

In some research reactors, natural water convection in the core can even remove heat from low operating power, and this possibility is provided for in the general operating rules for these reactors. This enables valve operation and natural water convection in the core to be checked in normal reactor operating conditions. In reactors whose core is cooled in normal operating conditions with a downward water flow (high-flux reactor in Grenoble, ORPHEE), natural convection does not start immediately upon shutdown, because it requires the flow direction in the core to be reversed. For such reactors, this switch of direction obviously needs to be checked in commissioning tests and in operation.

For high-power research reactors such as the $100 \mathrm{MW}$ Jules Horowitz Reactor which is currently under construction at the Cadarache site, the level of residual heat released means that forced core cooling flow must be provided for several hours after reactor shutdown. Residual heat removal requires the use of "active" systems, both normal systems and safeguard systems for accident conditions. These safeguard systems include pumps and heat exchangers that exchange heat with one or more cooling systems. Given the safety-importance of such systems, the design, manufacturing and operating requirements are high and include specifications concerning in-service monitoring and maintenance. These systems are provided as redundant, with each system geographically separated and individually capable of removing all residual heat. They are 
provided with back-up electrical power via batteries and generators, and the pipe lengths and number of flanges and unions are kept low in order to reduce risks of leakage or pipe break.

For research reactors whose core sits in a pool, the water inventory in the pool needs to be maintained in all possible situations. Maintaining this water inventory is one of the ways cooling function is managed, and is also a protection against ionising radiation. A drop in water level in the pool may be due to a leak in it or a leak or break in a circuit connected to it. To prevent a water level drop, one design provision is to ensure that all pipes penetrating the structure of the pool open out above the level of the reactor core. This applies in particular to the auxiliary systems, such as the "hot layer" system referred to below in section 7.3.3, which remove surface impurities from the water in the pool, or the make-up water system that makes up for water that evaporates from the pool.

In neutron beam reactors, the neutron channels (see figure 7.4) that penetrate the pool walls cannot comply with this provision because, by definition, they are located on the same level as the reactor core. A neutron beam channel is therefore fitted with:

- a "window" (in most cases ${ }^{192}$ ), which is a membrane made of a sufficiently neutron-transparent material (usually aluminium or an aluminium alloy), which separates the in-reactor part of the channel from the outside air in the areas used by scientists; this window is designed to withstand accidental loading (such as ingress of water into the channel in the event of a thimble failure, or a possible BORAX-type accident in the core);

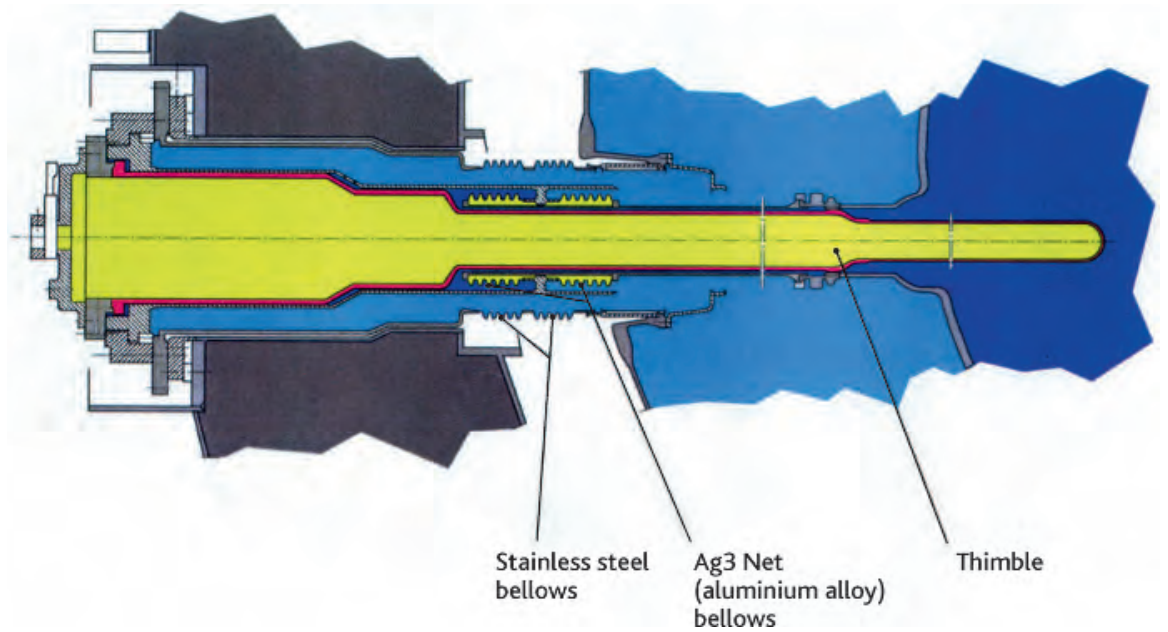

Figure 7.4. Section through a thimble from the high-flux reactor in Grenoble. (c) ILL.

192. In the the RHF, for example, thimbles $\mathrm{H6}$ and $\mathrm{H9}$, which are used for inserting samples onto a trolley where they will receive the highest neutron flux close to the core, do not have "windows". In this case, the redundant seal is provided by other valves downstream of the safety valve. 
- a shut-off valve at the pool wall, or "safety valve" that is permanently open when the reactor is in operation, to provide a double leaktight. If water enters the thimble, a time switch can trigger valve closure.

Furthermore, the channels have neutron beam shutters, which are separate components, in addition to the "windows" and safety valves described above.

Given the water flow velocity in the reactor coolant system, any leak in a portion of the system outside the pool could drain the system through a siphon effect. To avoid this, the reactor coolant pipes have vacuum relief valves (see figure 7.5 ), whose role is
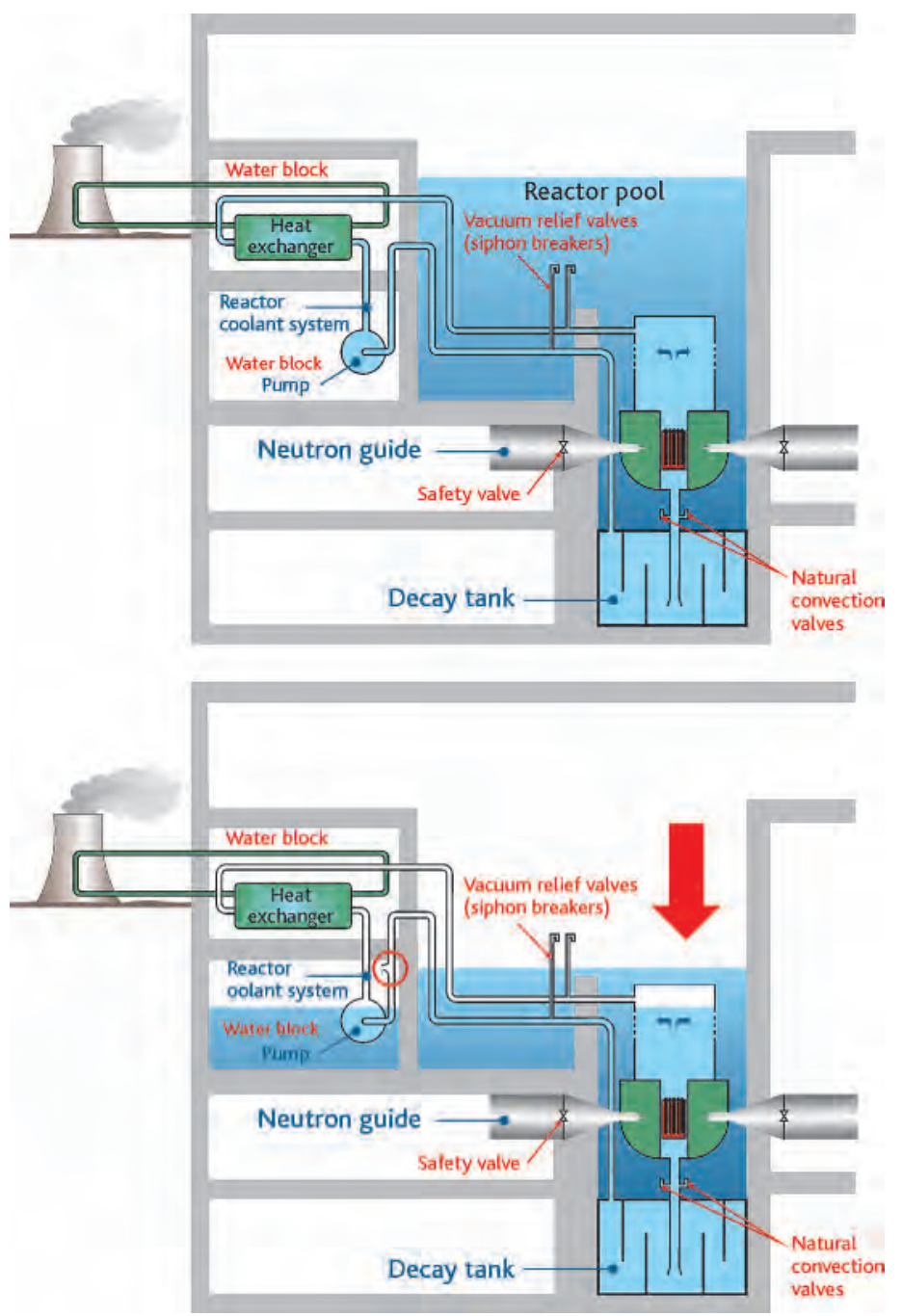

Figure 7.5. Schematic diagram showing "passive" siphon breaker systems on a cooling system. (c) Georges Goué/IRSN. 
to break the siphon effect, by letting air into the leaking system (either passive or active air injection using a valve or similar device).

In some French research reactors, including pool-type reactors such as OSIRIS, ORPHEE and JHR, a concept referred to as a "water block" is used to mitigate against the risk of reactor core uncover following a break on the reactor coolant system (see figure 7.6). This concept ensures that all rooms containing portions of a system in which a break or leak could drain the pool are sufficiently leaktight and of an appropriate volume. If there is a break of the system, water flows out into a leaktight room until it is completely filled. The quantity of water lost to the leak is limited by the volume of the room, which stops the pool from draining while it is still at a high enough level to prevent uncover of the fuel elements as a result of the reactor coolant pipe break. This however requires either strict operating procedures (doors kept closed), or design
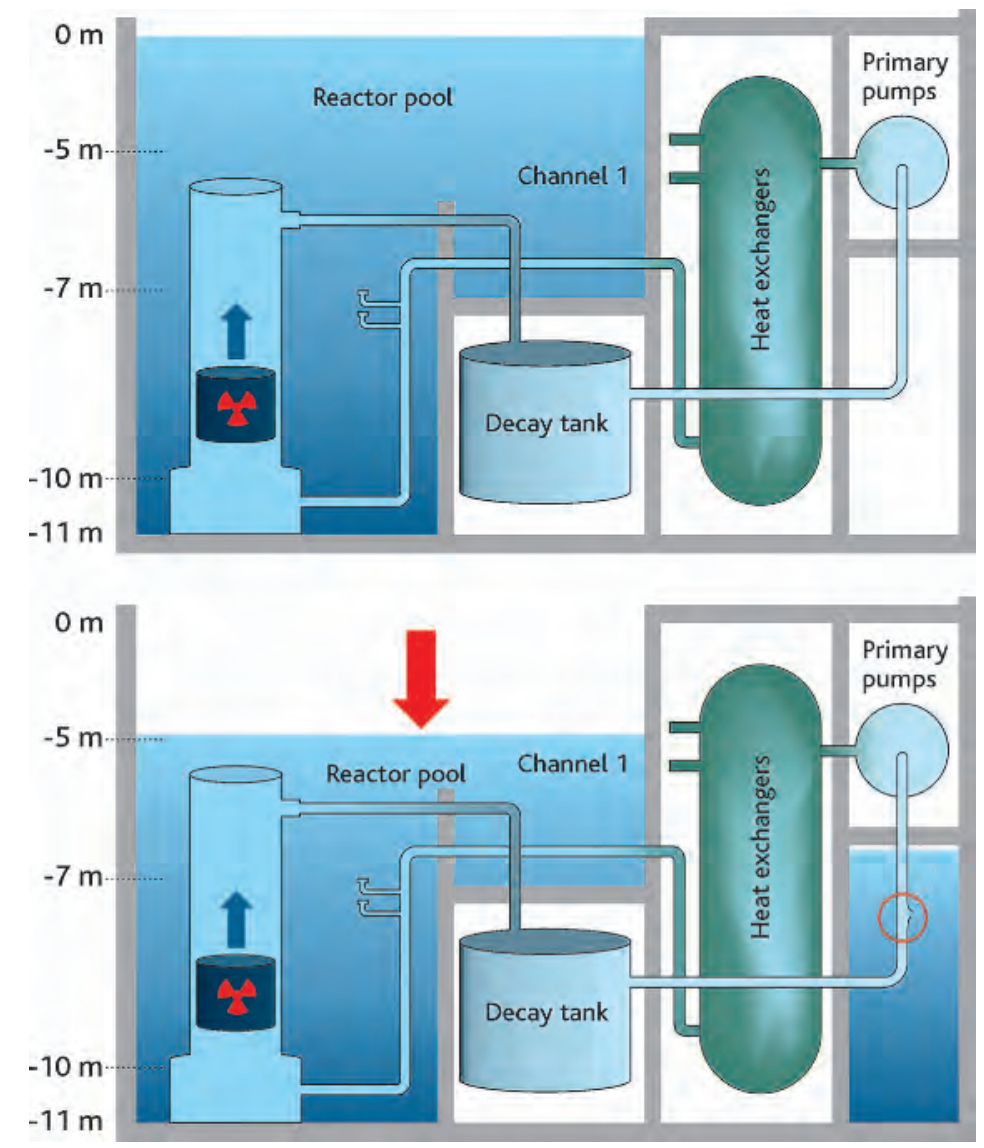

Figure 7.6. "Water block" concept: limiting water level drop in the reactor pool in the event of a coolant system break. (C) Georges Goué/IRSN. 
provisions (door position reported in the control room), to ensure that the relevant rooms remain tightly sealed.

Finally, the reactors pools of French research reactors that use a uranium-aluminium alloy-based fuel are designed to withstand the steam explosion from a BORAX-type accident.

\subsubsection{Confinement of radioactive substances}

The key principle for confining radioactive substances, both for research reactors and for all other basic nuclear installations in France, is to place several "barriers" between the substances and the environment. For the nuclear fuel, these "barriers" are as follows:

- the first confinement barrier is the metal cladding around the fuel elements;

- the second confinement barrier is generally the coolant circuit boundary; however, as previously mentioned, in some research reactors, this system is connected with the reactor pool and therefore does not form a proper confinement barrier;

- beyond this, the final confinement barrier comprises the building housing the reactor core (the lowest part being the basemat, the reactor pool floor or some rooms, depending on facility configuration).

It is important to highlight here that this final confinement barrier generally includes the building itself, providing "passive" confinement, and a ventilation and filter system, providing "dynamic" confinement.

Moreover, in neutron beam reactors, the heavy water systems contain tritiated water formed by neutron activation of deuterium atoms in heavy water. This requires these systems to be appropriately sealed, given the radiological risks associated with tritium.

The reactor building must be designed to restrict leakage into the environment. There must therefore be as few as possible piping or cable penetrations, and these must be sealed with appropriate materials. Since a building is never perfectly airtight, its passive confinement is generally supplemented by a dynamic confinement system, maintaining a slight negative pressure in the building compared with the outside pressure (the RHF is a special case, discussed later). With this pressure differential, air will preferentially leak from the outside in to the building. Such "active" confinement systems require equipment such as extractor and blower fans, along with filtration systems (high-efficiency particulate [HEPA] filters and iodine filters) that trap dangerous substances before they can be released into the environment in the air.

In the event of an incident or accident involving the dispersal of radioactive substances inside the reactor building, the ventilation systems are usually turned off automatically with reactor shutdown, in order to initially provide static confinement of the radioactive substances. This reduces the associated risks because the short-lived fission products begin to undergo radioactive decay. Ventilation systems 
can be turned back on later, in order to filter air releases. However, during the static confinement phase, pressure increases inside the building because the air is heated by the suspended fission products, and some of the building's atmosphere may escape into the environment without being filtered, through "natural" leakage. Some research reactors, such as ORPHEE and JHR, therefore have a "leakages grouping area", which is a room adjacent to the reactor building that contains a ventilation system with filters. All piping and cable penetrations from the building enter this room (see figure 7.7), enabling it to collect the majority of leaks from the building before they are released into the environment.

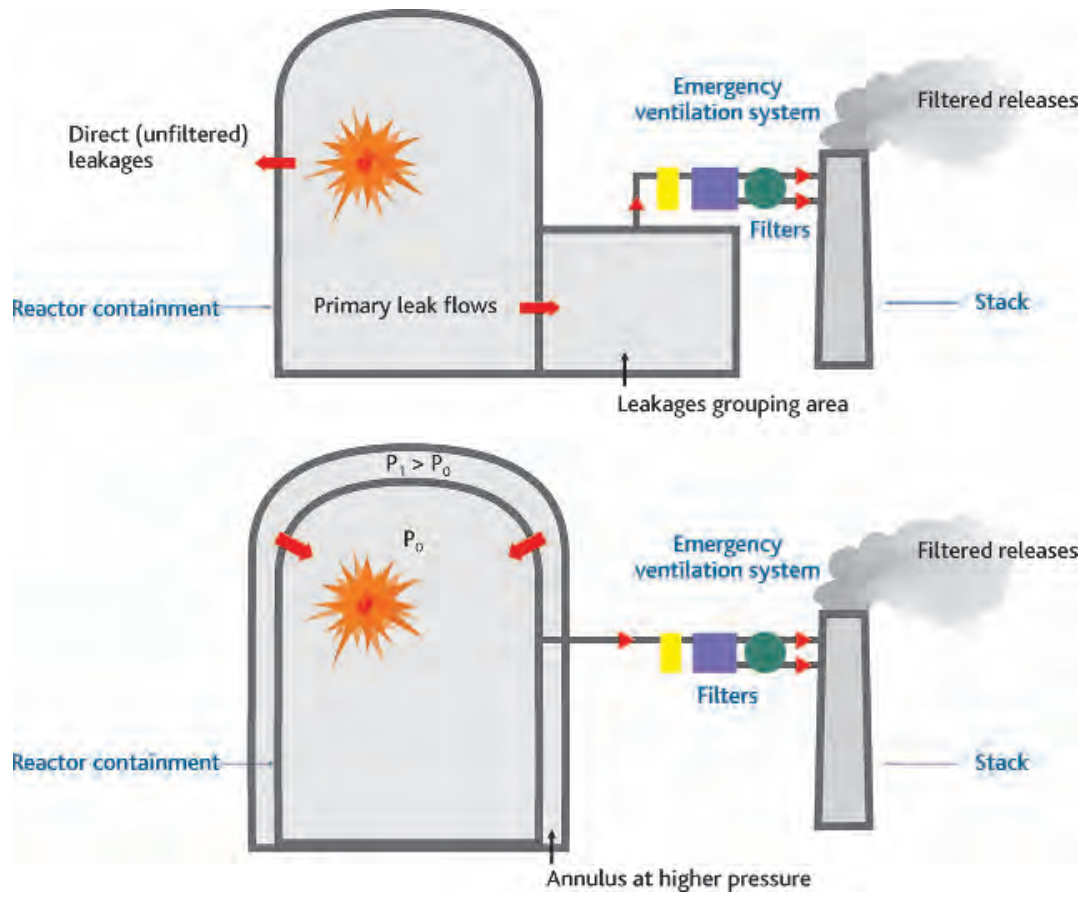

Figure 7.7. Schematic diagram of provisions implemented to prevent direct leakage from a reactor building atmosphere into the environment. @ Georges Goué/IRSN.

Another provision is to create an annulus around the reactor building, in which the air pressure is always higher than inside the building. This approach was adopted for the RHF.

The choice of strategy for this ultimate confinement (third barrier and associated systems) depends on the composition and quantities of radioactive substances that could be released in accident conditions, and on the kinetics of such releases. Other considerations such as the proximity of local communities may also feed into the choice. This is a key decision for reactor new-build projects, and the choice must feature in the Safety Options Report which is filed with the Safety Authority for examination. 
It should also be noted that most research reactors have an emergency ventilation system to remove air at a lower flow rate and maintain a slight negative pressure in the reactor building after the normal ventilation system shuts down. This emergency ventilation system, fitted with HEPA filters and iodine filters, filters any radioactive releases, spreads them out over time and measures the level of radioactivity released. There is an automatic switchover from normal to emergency ventilation if a predetermined level of radioactivity is exceeded in the reactor building.

Two further features of some research reactors are also worth a mention:

- as mentioned above, the reactor coolant system of some research reactors is connected to the reactor pool. In order to protect operators or scientists working on the edge of the pool, these reactors have a "hot layer" system, which sends hot water $\left(40^{\circ} \mathrm{C}\right)$ to the top of the pool and removes it again from the top layer by suction on the other side. This "hot layer" has a depth of between $2 \mathrm{~m}$ and $4 \mathrm{~m}$, and the water recovered is treated continuously using ion exchange resins. The temperature differential created by this "hot layer" keeps radioactive substances down in the colder water lower in the pool;

- in some cases, such as the CABRI reactor (see figure 5.11), the reactor coolant circuit may run partly outside the reactor building; in this case, both the reactor coolant tanks outside the reactor building have a double lining and a retention $\operatorname{tank}^{193}$.

\subsubsection{Criticality risks}

A criticality accident can expose people close to the affected area to severe levels of radiation, and can even cause death. Measures are therefore taken to maintain subcritical conditions whenever criticality is not required, whether in the reactor core when it is shut down or in any other part of the facility using plutonium, uranium that is more than $1 \%$ enriched in uranium-235 or certain minor actinides such as curium or americium.

A sufficient quantity of fissile nuclei are required to trigger a chain reaction in any given medium. This means that in any medium there is a mass below which a self-sustaining fission reaction is not physically possibly. One way of preventing a chain reaction is therefore to restrict the mass of fissile materials ${ }^{194}$. The limitations imposed by this control strategy, when used in isolation, are usually fairly stringent, and it is thus applicable to a container, glovebox or laboratory that uses small quantities of fissile materials, but not, on its own, to rooms containing larger quantities of fissile materials, such as critical assembly fuel element storage areas.

In such cases, two simple principles are used to guarantee subcriticality:

- reducing neutron generation as much as possible by reducing the likelihood of fission reactions;

193. Tanks with very low water pressure.

194. An isotope is referred to as "fissile" if its nucleus can split (undergo fission) under bombardment from fast or slow neutrons. The only naturally-occurring fissile isotope is uranium-235. 
- encouraging as far as possible neutron leakage out of the medium in question, or neutron absorption by non-fission capture ${ }^{195}$.

\#FOCUS

\section{Slowing down the neutrons - key to maintaining \\ a chain reaction}

When they are generated in a fission reaction, neutrons have high kinetic energy (around $2 \mathrm{MeV}$ ), and the probability of causing a further fission is fairly low. However, as they move through material, the neutrons collide with nuclei in the medium and gradually lose some of their energy. This increases the probability of their capture and of further fission. The lighter the nuclei that the neutrons encounter, the more they are slowed down (the slowing-down process is often called "moderation"). Hydrogen is thus a very good moderator.

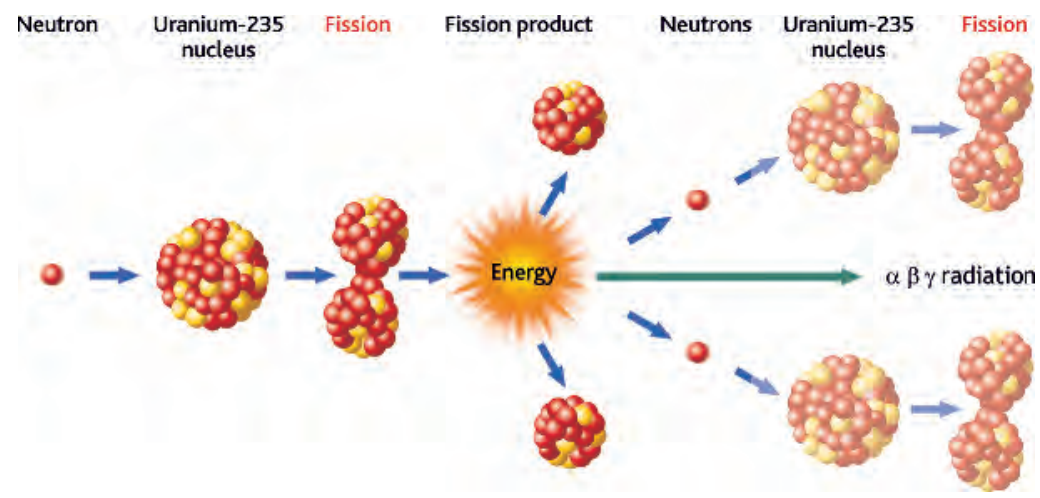

Figure 7.8. Uranium-235 fission reaction. (C) Georges Goué/IRSN.

Water and hydrogenated materials are "moderators" (see focus), increasing the likelihood of uranium-235 fission, and therefore raising the criticality risks. Water may therefore be prohibited in some rooms, even as a fire-fighting substance, with a specific low-hydrogen extinguishing powder used instead. This is a criticality control method that involves limiting moderation.

195. Neutrons can be captured by nuclei of the structural metals, the moderator, the fuel cladding, absorber rods or even by fissile nuclei without triggering fission. These neutrons are hence lost for the chain reaction. The affected materials are activated by these captures (meaning they have become radioactive). 
The potential presence of hydrogenated materials in waste or around fuel must be taken into consideration in criticality studies.

The geometric characteristics of the equipment in which the fissile materials are contained have a significant influence on neutron leakage. The geometric "criticality control method" has the advantage of low sensitivity to human operating errors. However, it must be adopted from equipment design phase wherever possible, taking into account any hazards and conditions that could change the "geometry" of fissile materials, such as corrosion and accidental deformation through temperature increases, earthquakes, etc. If such equipment is changed or modified, measures must be taken to ensure that appropriate geometric characteristics are retained.

When neutrons exit a fissile material, they continue moving and may end up returning to their original fissile medium because of collisions with the nuclei of these materials (neutron reflection). Some of the neutrons leaving a fissile medium may also enter a nearby piece of equipment that also contains fissile materials, and cause fission reactions there (neutron interaction). Both these phenomena must be taken into account in studies on criticality risks.

Finally, criticality risks can also be managed using "neutron poisons" such as boron, cadmium or hafnium, which are very good for absorbing neutrons.

Decisions as to the criticality control method(s) to be used for a facility (e.g. fuel element storage pool, fuel rodlets or platelets storage area for the MASURCA assembly) may lead to strict restrictions on specific parameters, taking account not only of normal conditions but also potential abnormal conditions (such as earthquakes) that may affect the fissile materials. Materials that may be present in the vicinity of the nuclear materials being studied obviously have to be taken into account in criticality studies, because of the potential neutron interactions that may increase criticality risks.

Fuel elements are often handled by operators in a research reactor, and in some handling phases, criticality risk prevention is largely based on organisational and human measures to ensure compliance with the restrictions defined in the criticality studies. Such measures may include hold points in handling operations or, for instance in the case of MASURCA, the use of sizing moulds that do not allow more than a permitted number of fuel strips. These provisions were adopted following a 2005-2006 safety review that analysed criticality risks at the facility in the light of organisational and human factors.

\subsection{Hazards}

As with other basic nuclear installations, there are two types of hazards to consider:

- internal hazards, originating inside the facility,

- external hazards, originating outside the facility.

\subsubsection{Internal hazards}

The main internal hazards that can affect research reactor safety are flooding (following a pipe or tank leak or failure), fire and explosions and load drops. Since 
research reactors do not usually use high-pressure coolants, the risks of pipe "whip"196 are lower than for pressurised water reactors, for instance. These issues may however need to be considered for test loops. The reactor safety consequences of each type of hazard have to be assessed and appropriate prevention and mitigation measures taken.

Electrical components are deemed to be sensitive to internal flooding, since any contact with water can lead to short circuits and outbreaks of fire.

Any rooms that contain, or could potentially contain, fissile materials are also sensitive to flooding, because of the criticality risk.

Provisions such as low walls at the entrance to rooms and placing fissile materials storage cabinets at a certain height may be adopted. It is also important to avoid routing water pipes through sensitive rooms or rooms containing flood-sensitive equipment, as far possible.

A waterproof coating may be fitted in some areas of a facility, as appropriate, to prevent internal flooding from water that could come in from outside the building as external flooding at ground level or through a rise in the groundwater level.

Alongside flood risks, the large range of electrical equipment used for experiments may make it harder to manage fire risks in a research reactor. Fire risk management is necessary throughout the duration of facility operation. A fire took place in August 1979 in the room housing the electronic equipment cabinets for the hodoscope ${ }^{197}$ at the CABRI reactor. The fire was found to have been caused by a transformer in the bottom of one cabinet overheating. Because all sides of the cabinet were closed, the fire had already developed significantly when the detector sounded the alarm. With dark, corrosive smoke filling several rooms quickly, the investigations and firefighting efforts were significantly hindered, since the most active area of fire was hidden by the electronic cabinet, and the rooms had no smoke extraction system. This resulted in confusion for quite a long period of time as to which room the incident started in. The fire was eventually fought with water spray systems and fully extinguished only after two hours. All the hodoscope electronic cabinets ${ }^{198}$ were destroyed and the hodoscope could not be used for eight months.

A Basic Safety Rule was established in 1991, specifically for fire risk management in research reactors (see section 6.2). More recently in 2014, an ASN decision ${ }^{199}$ established rules for fire risk management in all basic nuclear installations in general. Four levels of application of the defence in depth principle are outlined:

196. Complete pipe rupture can lead to movements known as "whip" in the pipe branches on either side of the break. The violence of the whipping depends on the fluid pressure inside the pipe system.

197. This device is used to observe the behaviour of fuel elements (specifically movements of the fissile material) placed in the CABRI reactor test section in experiments that simulate accident conditions leading to fuel melt and liquidation.

198. Some documents also report damage to the reactor protection system relay due to the propagation of smoke.

199. ASN Decision 2014-DC-0417 dated 28 January 2014. 
- "preventing outbreaks of fire;

- detecting and quickly extinguishing outbreaks, firstly to prevent them leading to a full fire and secondly, to return to normal operating conditions or, failing that, achieve and maintain a safe state ${ }^{200}$ in the facility;

- limiting the hazard and spread of any fire that cannot be controlled, in order to minimise the impact on nuclear safety, and to enable a safe state to be achieved and maintained in the facility;

- managing accident conditions resulting from any fire that cannot be controlled such as to limit consequences for people and the environment."

The first three levels of these rules are about avoiding jeopardising fundamental safety functions. Any equipment performing such functions must obviously be protected from the consequences of a fire.

As for other basic nuclear installations, prevention of the outbreak of fire in research reactors involves using low-flammable materials as much as possible, and limiting combustible materials to the quantities strictly necessary in those rooms or areas designated for their storage such as pools or warehouses, etc.

Facilities are also equipped with fire detection systems that notify operators of any outbreaks of fire and automatic actions may be triggered, such as stopping air supply from the ventilation system and closing fire dampers to limit the spread of the fire.

Finally, research reactors have firefighting systems that are appropriate to the types of fire that may occur and the equipment to protect. There are however various specific features that are worth highlighting. For example, in core fuel element handling and storage areas at the MASURCA facility (for fuel rodlets or platelets, solid sodium etc.), firefighting systems using graphite-based powders are installed for fires that could involve solid sodium elements, given the energy-releasing nature of the sodium-water reaction (sodium fire, emission of oxide and peroxide sodium aerosols). Moreover, as has already been stated in section 7.3.4, water may be prohibited in some rooms with criticality risks because water is a neutron moderator. This applies to the fissile element storage and handling areas in the MASURCA storage and handling building.

Facilities are organised into fire compartments to prevent the spread of any fire that is not quickly extinguished. A fire compartment is a clearly contained volume, closed off with walls such that a fire inside a compartment cannot spread to the outside (or vice versa) during a certain period of time, allowing firefighting systems to be used. By using fire compartments, common mode loss of a safety function can be avoided, as long as the function is provided by two redundant systems located in two different fire compartments. This is usually the case for a nuclear reactor protection system (that triggers reactor scram) and for electrical power supply systems, etc.

200. ASN Guide No. 22 on the design of pressurised water reactors, released in 2017, defines a safe state as follows: "stabilised condition of a facility in which subcriticality, residual heat removal and the containment of radioactive substances can be maintained in the long term." 
In some older research reactors however, fire compartmentation was not planned in design phase. Special attention is therefore paid to this issue, especially in safety reviews, when the possibility of improvements and upgrades in this area can be specifically examined.

Some fire compartmentation non-conformities have been discovered in basic nuclear installations in general, by the facility operators themselves or during inspections by the French Nuclear Safety Authority (ASN). Further study is ongoing into reducing firerelated risks, focusing on the possibilities of unburned gases and soot spreading outside of the compartment in which the fire started, such as to jeopardise the redundant trains of safety-classified systems in other fire compartments. IRSN is continuing to perform research and development work on this topic ${ }^{201}$.

For research reactors, the prevention of explosion-related risks is generally based on reducing the possible sources and distancing them from any safety-important equipment. Explosion risks associated with the experimental devices placed inside research reactors (including the "long-term" associated equipment such as "hot sources" and "cold sources") are discussed later.

Load drops are events that can occur during the handling of relatively heavy items (fuel elements or assemblies, experimental devices, transport packaging, etc.). Prevention of such events involves adopting robust design provisions and ensuring in-service monitoring of lifting equipment. However, it is not really feasible to rule out any possibility of load drops. For this reason, metal plates on shock absorbers (sometimes referred to as "resilient bearing pads") have been fitted to some reactor pools in order to protect their bottom or parts of their bottom from load drops. Likewise, some research reactors have "lifting accompaniment devices", which slow the fall of any load being handled if the lifting equipment fails.

\subsubsection{External hazards}

External hazards may have human ${ }^{202}$ or natural causes. Manmade hazards are related to the presence of industries and transport routes in the vicinity of the facility. Natural hazards will depend on the site at which the research reactor is built, and may include earthquakes, flooding, fire, lightning, violent winds and tornados and extreme temperatures.

When a new research reactor project is considered, the prevention of external hazards is firstly based on the choice of site, avoiding choosing a site that will engender insurmountable difficulties for facility protection and design. It is important to determine the external events that could constitute hazards for the facility; the determination method will vary depending on the hazard type considered.

It should be noted that some research reactors have been close to or on the site of universities or other academic centres (e.g. the Strasbourg university reactor, which has now been shut down).

201. See publication "Current state of research on pressurized water reactor safety", Science and Technology Series, IRSN/EDP Sciences, 2017.

202. Malicious acts are not covered in this document. 
For hazards caused by the industrial environment (e.g. chemical plants) or human activities (all forms of transport, including civil and military aviation), the hazard-causing events are usually identified on the basis of a probabilistic-type analysis. If the likelihood of occurrence is very low (of the order of $10^{-7}$ per year), current practice under the fundamental safety rules (see chapter 6) is to consider the hazard improbable enough to disregard in terms of facility protection or design verification.

The main risks associated with land-based transport routes and the industrial environment around a research reactor are a gas cloud explosion (explosion of a truck carrying hazardous materials or a warehouse storing hazardous materials) or a toxic gas cloud drifting to the facility. These risks were closely studied for the RHF at Grenoble, which is located close to an industrial area, a motorway and a railyard. In addition to the design provisions, supplementary considerations are taken into account as necessary during safety reviews, including an analysis of preparedness for potential emergency situations (crisis management).

The natural hazards considered are determined on the basis of available historical data, which is then extrapolated to define hazards in pessimistic terms, which may be associated with a given recurrence period.

ASN Guide No. 13, which was released in 2013, discusses how to determine trigger events relating to the various possible causes of external flooding and how to define the appropriate protection provisions ${ }^{203}$. For every research reactor site, all possible causes of flood risks need to be explored, including heavy rainfall, rain-induced river level rises, flash flooding from dam failure and rises in the groundwater level, etc. French research reactors are not built on the coastline, which rules out risks from high tides and tsunamis, etc.

With regard to the risks of heavy rainfall, rainwater drainage systems are designed to ensure that no water enters the facility and, if necessary, sills may be installed at certain doors.

The safety of the RHF at Grenoble in the event of dam failure, given its location at the confluence of the Rivers Drac and Isère, both of which have a number of dams, is an issue that has been analysed repeatedly in periodic reviews as well as in the complementary safety assessments (stress tests) carried out in France in the wake of the Fukushima Daiichi nuclear powerplant accident. This issue of safety reviews is addressed in section 9.2 .

The following paragraphs describe in greater detail the way in which seismic risks are managed. Given their locations, the risk that an earthquake of significant intensity may occur can be relatively high for some research reactors. This type of hazard, it should be noted, affects the whole of a facility simultaneously and can therefore lead to common mode failures.

203. On this subject, see the 2013 IRSN Report "L'aléa inondation - État de l'art préalable à l'élaboration du guide inondation pour les installations nucléaires". 
With regard to seismic risks, until the 1970s, research reactors built in France were built under the then-applicable earthquake protection rules ${ }^{204}$, which were not specific to any particular type of building, such as a basic nuclear installation. In 1974, when nuclear power reactors were being developed in France, the CEA Nuclear Safety Department ${ }^{205}$ drafted report DSN50 (on behalf of the standing group of experts for nuclear reactors) entitled "Protecting powerplants from earthquakes". The report surveyed relevant French and international practice and made a number of proposals, especially about how to determine which ground response spectra ${ }^{206}$ to use (with a dynamic analytical method) to assess the "response" of the structures to an earthquake. These proposals formed a basis for facility operators to work with, and prefigured fundamental safety rule RFS I.2.c, which was released in 1981 by the Nuclear Facility Safety Central Service for pressurised water reactors, proposing a deterministic method that would be acceptable for determining which seismic motions should be taken into account in earthquake design for such reactors. In 1992, fundamental safety rule RFS I.1.c extended this method to be applied to all basic nuclear installations, including research reactors. This method starts with surveying the strongest known earthquakes in the area around the facility site, based on available geological and seismological data, in order to determine the intensity of a "maximum historically probable earthquake". The intensity is increased, to give what is known as a "safe shudown earthquake", which is used as a reference for facility safety. In 2001, a new fundamental safety rule (RFS No. 2001-01), drawn up with the help of IPSN experts, was released by the Nuclear Safety Authority after several years of discussion between relevant parties. This new Rule maintained a deterministic approach, but also introduced some further developments about how paleoearthquakes and site effects should be taken into account. Moreover, for sites with very low seismic risks, a minimum spectrum is defined, for which peak ground acceleration (PGA: acceleration corresponding to infinite frequency) is set at 0.1 times gravitational acceleration $(\mathrm{g})^{207}$.

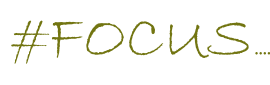

\section{Paleoearthquakes \& Site effects}

Paleoearthquakes are strong earthquakes that occurred in ancient times. They can be identified through the traces they have left in geological deposits in the Quaternary. The purpose of studying them is to understand and characterise the occurrence of such earthquakes and to supplement knowledge about seismicity

204. Recommendation AS 55 (1955), drafted following the Orléansville earthquake in Algeria in 1954, earthquake protection rules PS62, 64, 67, 69, etc.

205. The IPSN was only established as part of CEA in 1976.

206. Response (in terms of accelerations) of resonators at various natural frequencies, under the effects of the earthquake in question.

207. For zones of moderate seismicity, accelerations can be up to $0.3 \mathrm{~g}$ approximately. For highseismicity zones such as Japan or Turkey, accelerations can be up to a range between 0.4 and $0.6 \mathrm{~g}$. 
around a site, beyond the period for which instrumental data (over the last century) or historical records (over roughly the last millennium in France) are available.

Site effects that require study are potential amplifications of seismic motions due to the presence of a layer of low mechanical strength soil close to the surface (up to 30 metres below ground level).

In addition, in some specific cases, complex geometry or thick sedimentary layers (e.g. a sedimentary basin) may cause amplification or temporal prolongation of the seismic motion. These are referred to as site-specific effects, and are not caused only by soil properties in the first 30 metres below the surface.

Site effects have to be especially taken into account at a research reactor such as the RHF at Grenoble, because of the presence of an alluvial basin (figure 7.9,
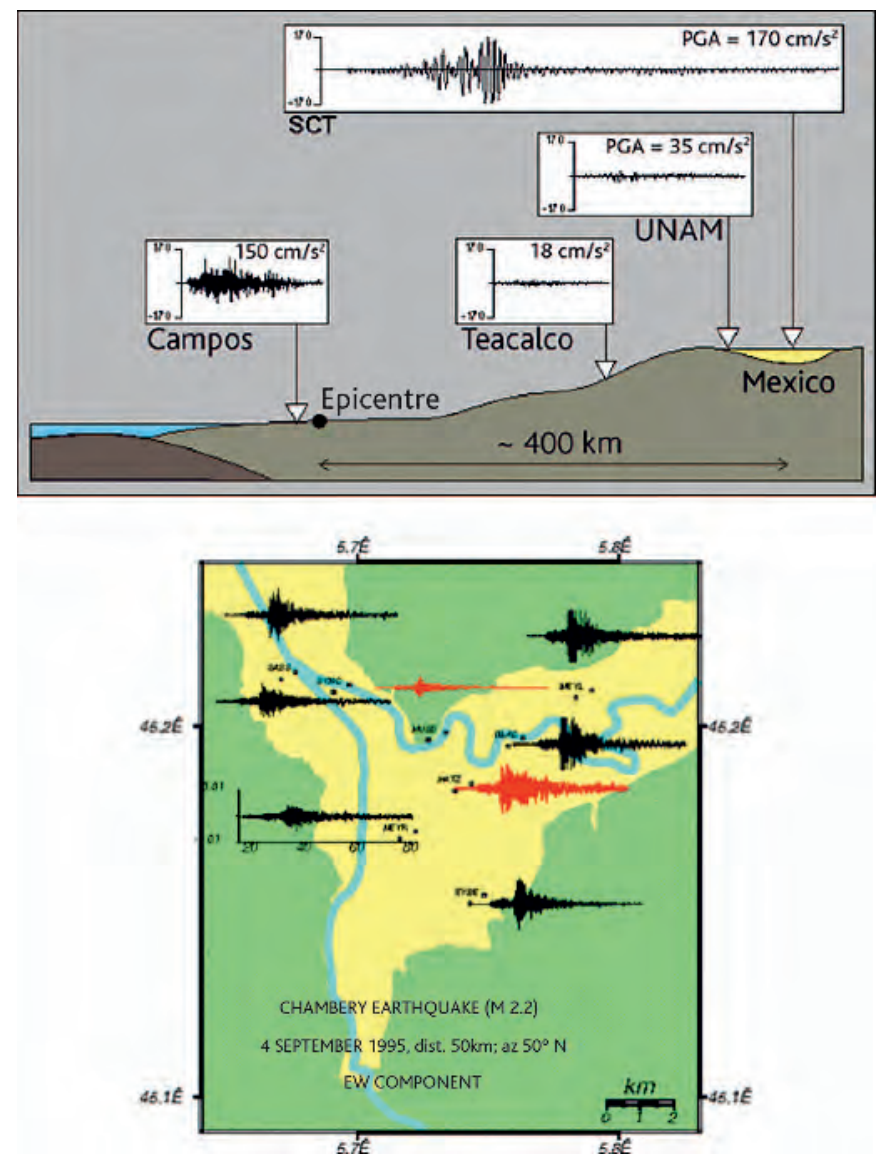

Figure 7.9. (Top) example of site effects in a coastal area of Mexico (C) J.F. Semblat, A. Pecker (IUSS Press, 2009); (bottom) example of site effects in the Grenoble basin during the 1996 Chambery earthquake. (C) All rights reserved. 
bottom side). The Saclay facilities are built on alluvial-type soil (but in a low-seismicity zone) and the Cadarache facilities are on a mixed rock/sediment soil.

Since all facility components are simultaneously affected by the seismic motions, facility safety relies on robust design ${ }^{208}$ of a set of key equipment that provides the main safety functions and if necessary, for a nuclear reactor, ensures it is placed in a safe state 209 . Alternatively, under an "event-level earthquake" approach (see section 7.1.2), design must ensure that components cannot themselves jeopardize safety-important equipment (e.g. by falling).

Calculations can be used to verify equipment behaviour under seismic loads (this method is used for concrete and metal structures). Full-scale testing on shaking tables can also be used for components such as natural convection valves or electrical cabinets or even safety absorbers (to check their ability to be inserted into the core zone in earthquake conditions, even if the core has been deformed by the earthquake).

Of the various equipment items that present potential hazards to safety-important equipment ${ }^{210}$, special attention is paid to handling cranes - particularly for research reactors whose core is directly accessible via the reactor pool (reactor coolant system connected to the pool). If a handling crane or its trolley were to drop, significant damage could be caused to the top part of a core, the instruments, absorber mechanisms, a pressurised circuit, reactor coolant pipe, natural convection valves, fuel elements or other components, and this could lead to a criticality accident or reactivity insertion accident, a sudden steam release or could prevent the safety absorbers from inserting properly into the core or the core from cooling properly. Some French research reactors have a system that detects seismic loads over a specific level and triggers a reactor scram, which reduces the consequences of an earthquake-driven crane or trolley drop. This system can ensure that subcriticality is maintained, but cannot necessarily guarantee that the fuel elements will be properly cooled, since these elements may have suffered deformation. It therefore seems essential to prevent any cranes or trolleys from falling, regardless of the cause. Design and manufacture must comply with tried-and-tested best practices, in-service inspections must be performed (including the statutory checks applicable to lifting plant and accessories), and operating rules must be complied with, to reduce any crane motions above at-risk zones to the strict minimum.

208. ASN Guide 2/01 dated 26 May 2006 addresses the way seismic risks should be taken into account in the earthquake-resistant design of basic nuclear installation civil works (with the exception of long-term radioactive waste disposal facilities.

209. See note footnote 191.

210. Some cranes may themselves be treated as safety-important equipment, requiring the general provisions adopted for such equipment, for example in-service inspections, maintenance, traceability of modifications, etc. 


\section{\#FOCUS \\ Improving knowledge on the behaviour of structures under seismic loading: handling cranes}

It is not easy to predict the behaviour of a crane and its trolley under seismic loads, with the potential to slip, slide and bump against its end buffers. There have been some difficulties in this regard during safety reviews, particularly when seismic motions were reassessed, leading to a significant increase in the loads to be taken into consideration. In the 2000s, IRSN and the CEA initiated studies on this issue, including tests on the AZALÉE shaking table at the CEA Saclay research centre (see figure 7.10). The focus of this work was to provide better understanding of the "response" of such complex structures to seismic motions, and to assess the robustness of the simplified methods used by facility operators to design structures.

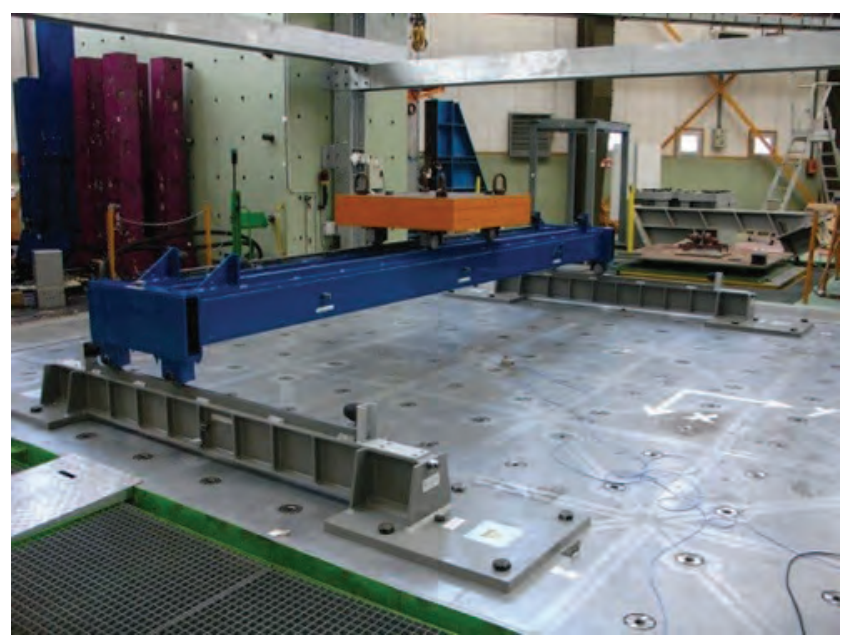

Figure 7.10. Handling crane undergoing testing on the AZALÉE shaking table at the CEA Saclay research centre. (C) CEA.

It should also be noted that there are systems that can be used to limit the motions that will affect a building and its equipment in the event of an earthquake. For instance, the reactor building basemat at the Jules Horowitz Reactor (JHR) on the Cadarache site, in a region with a history of strong earthquakes, such as the Lambesc quake in 1909, was laid on reinforced concrete bearing pads that were fitted with layers of elastomer and steel (see figure 7.11). This system (referred to as "seismic base isolation") reduces 


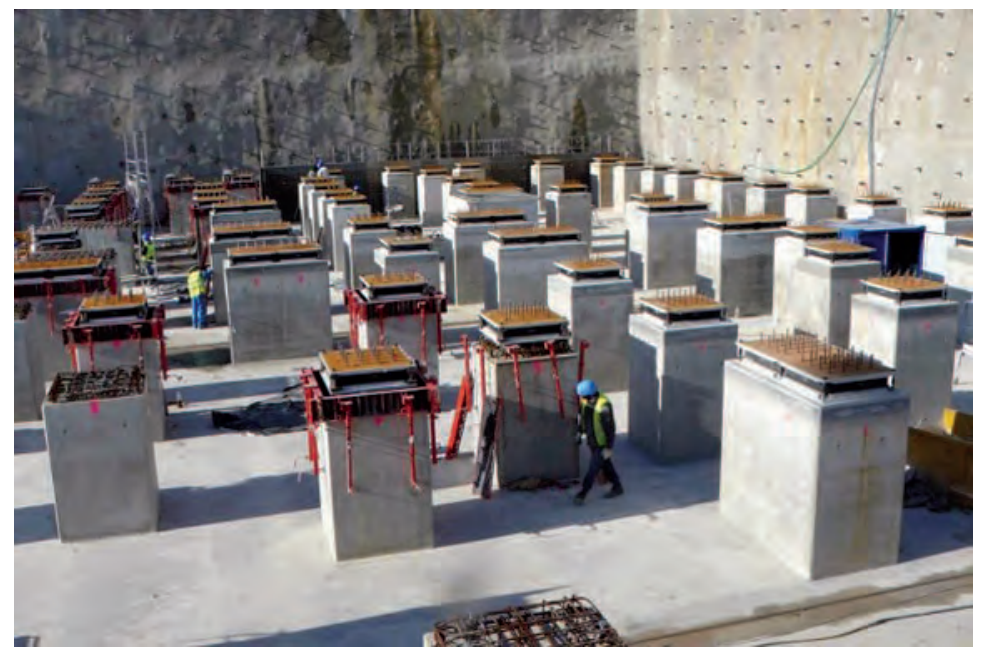

Figure 7.11. View of aseismic bearing pads during construction of the Jules Horowitz reactor (2009), from "Le Blog des Énergies". (C) DR.

high-frequency horizontal seismic loading ${ }^{211}$ for items such as floor-mounted equipment and handling cranes in the building. There is an obvious issue in keeping the bearing pads and elastomer layers in working condition throughout the duration of reactor operation, given their potential for ageing. It is therefore necessary to ensure that the bearing pads and elastomer layers can be replaced if any anomalies are detected during planned inspections.

JHR also includes a design provision that reduces impact risks from differential motions between the reactor building and auxiliary building. These two buildings, which make up the "nuclear unit" are built on the same basemat.

As stated previously, several French research reactors, such as MASURCA, RHF and $J H R$, feature accelerometers that send a signal to the reactor protection system. If a specific level of seismic loading is detected, the protection system triggers a reactor scram early enough to ensure that the safety absorbers are inserted far enough into the core zone when the bigger shocks come.

Research reactors are generally facilities with low sensitivity to weather-related hazards such as extreme heat or cold. For many research reactors, residual heat removal does not require any external heat sink other than the air, and their electrical power

211. The adoption of this base isolation system increases the amplitude of accelerations at the system's natural frequency (approx. $0.5 \mathrm{~Hz}$ ). France has experience in this area, since the four units at the Cruas-Meysse plant were installed on this type of base isolation system in 1977, because the ground response spectrum at the site was above $2 \mathrm{~Hz}$, the design spectrum EDF adopted for its nuclear powerplants. AFCEN has published a document on such seismic base isolation systems: "French Experience and Practice of Seismically Isolated Nuclear Facilities", PTAN RCC-CW 2015. 
requirements can, if necessary, be reduced to mere monitoring of the main safety-important parameters.

Research reactor buildings are fitted with lightning conductors, and lightning arresters are fitted to the electrical installations.

\subsection{Experimental devices and research reactor-specific equipment}

One feature of research reactors is that they include experimental devices or equipment, some of which is placed right in the reactor core, or in nearby peripheral areas. These devices and equipment items may include simple irradiation devices, more complex experimental circuits, neutron channels, "hot sources" and "cold sources". As stated in section 7.1.2, any interactions between these devices and components and the reactor core have to be analysed from a safety perspective, both in normal reactor operating conditions and in incident or accident conditions that could affect the reactor and the experimental devices.

Analysis of any experimental device or component requires the various potential "danger sources" to be identified, which could, in degraded conditions up to and including the complete rupture of the device or component, or its "removal" from the core zone, have a negative impact on reactor safety or radiological protection. These danger sources include fissile materials, absorbent materials, radioactive or toxic products, products that may be explosive in air, products that may be violently reactive in water, pressurised liquids or gases and high-temperature materials that may enter into thermodynamic interaction with water in the reactor core.

Depending on the properties of their materials, experimental devices or equipment may, in particular, modify core reactivity, since their materials may have neutron absorption (poison), reflection or moderation properties. The reactor protection system must therefore be capable of controlling any reactivity insertion in the core that could be caused by an inadvertent movement, such as an uncontrolled withdrawal from the core. For simple irradiation devices, this can be achieved through a design limit on the reactivity contribution of the relevant device or component; in such cases, the limit is also included in the technical operating specifications. For larger devices whose reactivity contribution cannot be sufficiently limited, design provisions are required to prevent or limit uncontrolled withdrawal (latching or hold-down devices).

For experimental loops, other risks may need to be considered, for example because of the use of pressurised fluids (e.g. to represent the conditions of pressurised water reactors - 155 bar [figure 7.12]) or reactive elements such as sodium which has a violent reaction with water. These loops may also contain molten materials, when the study of meltdown conditions is one of the objectives in an experiment on a fuel element.

Demonstration tests on mock-up assemblies may be necessary in order to assess the effects of explosion of an experimental loop on the nearby fuel elements in the reactor core. It is worth mentioning the OTHELLO loop for the OSIRIS reactor, which was designed for studies on high-temperature reactors (HTR): in the mock-up assembly, the loop had notches cut into it so that it would rupture at a given pressure. 


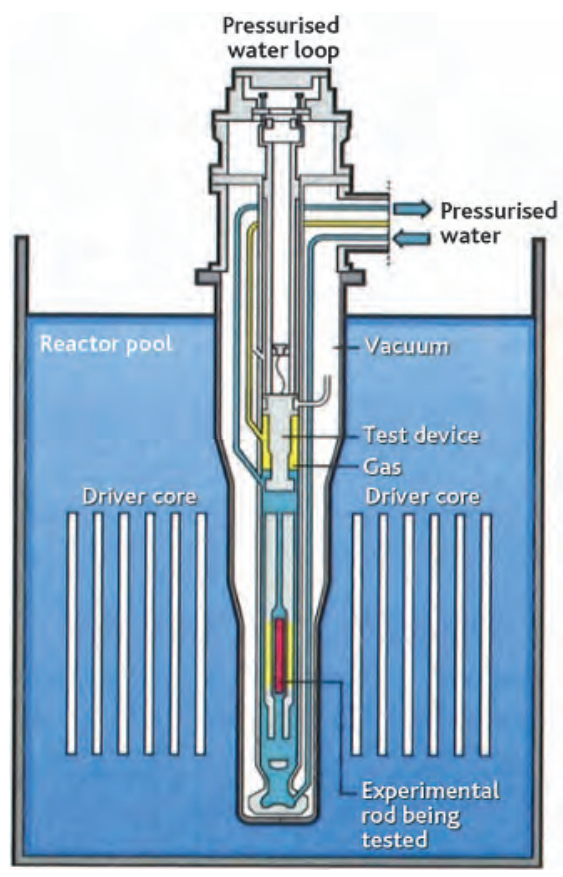

Figure 7.12. Schematic diagram of the pressurised water circuit in the CABRI reactor core. @ Stéphane Jungers/IRSN.

The "hot sources" and "cold sources" used in "neutron beam ouside" reactors generally contain liquid hydrogen $\left(H_{2}\right)$ or deuterium $\left(D_{2}\right)$ in the first case and graphite at more than $1,000^{\circ} \mathrm{C}$ in the second. Any failure of the casing(s) of such equipment would bring their contents into contact with water in the reactor core, causing a hydrogen, deuterium or steam explosion risk ${ }^{212}$ which could affect the core or the reactor confinement barriers. To prevent this risk, the main strategies are firstly to ensure there are "barriers" or casings of appropriate number and strength between the danger source and the reactor core, and secondly to manage the specific parameters of these devices (e.g. deuterium pressure, temperature).

One final key point in the design of experimental devices or equipment is material ageing. The materials will be subjected to neutron flux, which will gradually modify their mechanical properties. This applies especially, in "neutron beam outside" reactors, to the end parts of neutron channels (thimbles and their tips), which are constantly close to the reactor core. Neutron channels are generally made of aluminium or an aluminium alloy, or a zirconium compound such as Zircaloy. These materials are used for their neutron "transparency", but are weakened by exposure to neutron radiation. For this reason, such equipment (thimbles or core boxes, for example) must be replaced as appropriate during the service life of a research reactor. The effects of ageing can be

212. Steam explosion risk from thermodynamic interaction between graphite at $1,000{ }^{\circ} \mathrm{C}$ and water. 
anticipated by monitoring samples or specimens of the relevant materials that are irradiated in areas closer to the core than the experimental equipment itself (or actually in the core). This can help define the required frequency of equipment replacement.

\subsection{Radiological protection and waste substances}

\subsubsection{Radiological protection}

The French system of radiological protection is based on three major principles, which are part of the Public Health Code:

- justification of any activities that have a risk of exposure to ionising radiation;

- optimisation of radiation exposure to the lowest level reasonably possible, taking account of economic and social factors;

- limitation of individual radiation exposure doses.

French regulations establish annual individual dose limits for members of the public and workers (table 7.4).

Table 7.4. Exposure limits for members of the public and workers as a result of nuclear activities, as stated in the French Public Health Code (Article R. 1333-8) and Labour Code (Article R. 4451-13).

\begin{tabular}{|l|c|c|}
\hline \multicolumn{1}{|c|}{ Type of dose } & $\begin{array}{c}\text { Members of the } \\
\text { public } \\
\text { per year }\end{array}$ & $\begin{array}{c}\text { Exposed workers } \\
\text { (adults) } \\
\text { any twelve consecutive } \\
\text { months }\end{array}$ \\
\hline Annual effective dose & $1 \mathrm{mSv}$ & $20 \mathrm{mSv}$ \\
\hline $\begin{array}{l}\text { Equivalent dose to the skin, forearm, } \\
\text { feet and ankles (average dose per } 1 \mathrm{~cm}^{2} \text { area) }\end{array}$ & $50 \mathrm{mSv}$ & $500 \mathrm{mSv}$ \\
\hline Equivalent dose to the lens of the eye & $15 \mathrm{mSv}$ & $150 \mathrm{mSv}^{213}$ \\
\hline
\end{tabular}

In addition, the Labour Code requires facility operators to determine regulated monitoring zones around any sources of ionising radiation. These zones are defined in the "Zoning" Order of 15 May 2006 (table 7.5).

There are a wide variety of sources of ionising radiation in a research reactor and its related facilities, including fuel elements, neutron beams, start-up neutron sources, calibration sources and sources used for X-ray inspections. Likewise, a variety of operating activities can cause exposure to radiation:

213. The values given here are from ICRP Publication No. 60 from 1991. ICPR Publication No. 103 from late 2007 gives recommended values of $15 \mathrm{mSv}$ for members of the public and $20 \mathrm{mSv}$ for workers. French regulations were reviewed in 2018 (Health Code, Environment Code, Labour Code). 
Table 7.5. Limits for monitored and regulated zones defined in the "Zoning" Order (excluding natural irradiation).

\begin{tabular}{|l|c|c|}
\hline Type of zone & Colour & Effective dose \\
\hline Free access zone & & $<0.080 \mathrm{mSv} / \mathrm{mth}$ \\
\hline Monitored zone & & $<0.0075 \mathrm{mSv} / \mathrm{h}$ \\
\hline Controlled zone & & $<0.025 \mathrm{mSv} / \mathrm{h}$ \\
\hline Specially regulated controlled zone & & $<2 \mathrm{mSv} / \mathrm{h}$ \\
\cline { 2 - 3 } & & $<100 \mathrm{mSv} / \mathrm{h}$ \\
\hline Prohibited controlled zone & & $\geq 100 \mathrm{mSv} / \mathrm{h}$ \\
\hline
\end{tabular}

- reactor core loading or unloading,

- loading, unloading or modifying experimental irradiation devices or circuits,

- preparing fuel elements or assemblies, or irradiation or activation experiments,

- performing measurements on irradiated materials or fuels,

- in-service inspections, etc.

The facility operator uses analysis of the activities and of the characteristics of the ionising radiation sources to categorise rooms in the facility into "free access", "regulated", "specially regulated" or "prohibited" zones, in which the above limits must be complied with, through the implementation of technical and organisational measures. Figure 7.13 shows some examples of physical protection that might be used. Concrete blocks or lead walls are often used for this purpose (e.g. around the neutron guides in areas used by the physicists conducting experiments). For operations involving small irradiated objects, concrete or lead bricks will be placed around objects to which access is required, while still providing protection from ionising radiation. In some cases, operators may wear lead aprons.

In order to check compliance with the applicable dose limits, workers wear a measurement device appropriate to the nature of the ionising radiation at all times, providing ongoing exposure monitoring. Operational dosimetry ${ }^{214}$ is also used to warn them if

214. Operational dosimetry, also known as active dosimetry, involves real-time measurement of external exposure using a personal operational dosimeter. This device is provided and monitored by the Radiological Protection Officer under the responsibility of the Facility Manager. The electronic system in an operational dosimeter means that the dose received by the worker can immediately be read off. Measurements can be taken during a specific task or over a given duration (entry into a controlled zone). The devices have audio or visual alarm systems that are triggered if predefined doses are exceeded. This provides wearers with permanent information about the radioactive risk to which they are exposed. Wearers or the department responsible (using remote monitoring) can track and optimise exposure levels during the period of exposure itself. 


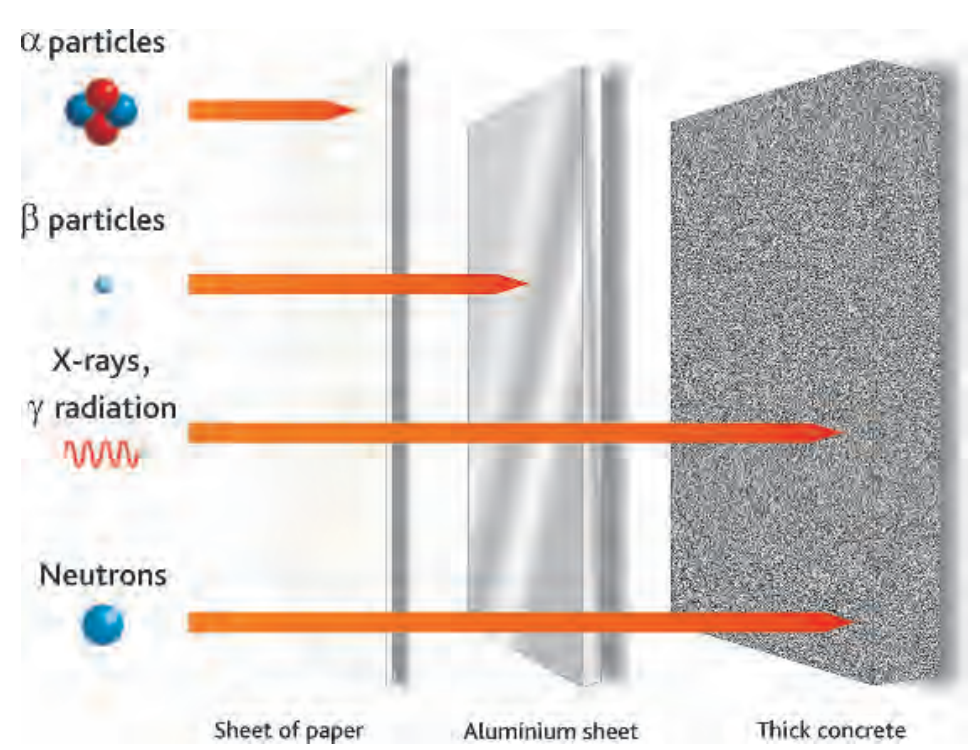

Figure 7.13. Effectiveness of various protections against different types of ionising radiation. (c) Georges Goué/IRSN.

a predetermined dose rate is exceeded, or a predetermined dose is exceeded over a certain duration.

If any work has to be performed on the facility, a safety analysis is performed, which includes a focus on radiological protection. A radiological protection optimisation study is conducted, which aims to ensure that personal doses, the number of people exposed and the likelihood of unplanned exposure during the work is kept as low as reasonably possible, taking into account economic and social factors. The main stages of the study are as follows:

- assess exposure conditions, including potential exposure occurrences if the operation does not take place as planned;

- select an appropriate upper limit for the dose restrictions;

- identify the possible protection options;

- select the best option in the applicable circumstances;

- implement the chosen option.

Operating experience is taken into account. The results are assessed, particularly in the perspective of future operations of the same type.

Optimising radiological protection does not necessarily mean minimising doses. Optimised protection comes as the result of an assessment and discussion, whereby the risks of the anticipated exposure are compared with the resources available for personal protection. The best option does not necessarily mean the one with the lowest 
doses. Moreover, radiological protection is not just about individual exposure levels; the number of people exposed must also be taken into account. The collective effective dose is a key parameter in optimising worker protection. When protection options are compared to achieve optimisation, careful consideration should be given to the distribution of individual exposure levels within the population of exposed people.

The experimental equipment or devices themselves may also be sources of ionising radiation. This is the case for example with experimental loops in which fuels are subjected to transients that could lead to cladding failure or fuel melt, contaminating the test circuits themselves. The components in these loops are fitted with biological shielding and specific handling equipment such as transfer casks are used to limit ionising radiation within the facility.

\subsubsection{Waste liquids and gases}

The management of waste liquids and gases from research reactor operation is generally similar to their management in any basic nuclear installation. However, two specific types of waste deserve a mention in this context:

- tritiated water produced from neutron capture by the deuterium in the heavy water used in "neutron beam outside" reactors (RHF and ORPHÉE);

- waste generated in experimental loops in which experimental fuel meltdown may occur or even be targeted.

Specific arrangements are put in place to manage these specific waste products (at ORPHEE, for example, there is a detritiation installation, and at the high-flux reactor in Grenoble there is a heavy water drum unloading installation, with the heavy water treated in a different facility).

The releases of waste liquids and gases from French research reactors are given in table 7.6, along with the annual limits established by official orders or decisions.

\subsection{Emergency preparedness and management (crisis management)}

Any significant release of radioactive substances that would require protection measures to be taken for local populations (e.g. evacuation, confinement to closed homes, distribution of stable iodine tablets, food restrictions) would mean that four initial levels of defence in depth had failed or proved ineffective. Specific measures are defined within the nationwide crisis management plans, which apply to all basic nuclear installations, including research reactors. These plans are not described in detail here $^{215}$, other than to mention the aspects that are specifically relevant to research reactors.

215. See for example: "La gestion d'une crise nucléaire : des responsabilités partagées" on the ASN website or "Face à un accident nucléaire", IRSN, Livrets des professionnels Collection - December 2008. 
Table 7.6. Releases from two research reactors (RHF, OSIRIS-ISIS) and annual limits.

\begin{tabular}{|c|c|c|}
\hline \multicolumn{3}{|c|}{ RHF } \\
\hline Type of releases & $\begin{array}{c}\text { Maximum annual value } \\
\text { over 2010-2015 period } \\
\text { Gaseous waste }(\mathrm{GBq}) \\
\text { Liquid waste }(\mathrm{GBq})\end{array}$ & $\begin{array}{c}\text { Annual limits } \\
\text { (Order dated 03/08/2007) }\end{array}$ \\
\hline Noble gases & 1,200 & 10,000 \\
\hline Tritium & 12,000 & 75,000 \\
& 370 & 1,000 \\
\hline Carbon 14 & 460 & 2,000 \\
& 0.3 & 1.5 \\
\hline lodides & $3.4 \times 10^{-3}$ & 0.1 \\
\hline Other $\beta \gamma$ emitters, aerosols & $1.3 \times 10^{-3}$ & 0.1 \\
& $3.1 \times 10^{-4}$ & 1 \\
\hline
\end{tabular}

OSIRIS-ISIS reactors (INB No. 40)

\begin{tabular}{|c|c|c|}
\hline Type of releases & $\begin{array}{c}\text { Maximum annual value } \\
\text { over 2010-2015 period } \\
\text { Gaseous waste }(\mathrm{GBq}) \\
\text { Liquid waste }(\mathrm{GBq})\left(^{*}\right)\end{array}$ & $\begin{array}{c}\text { Annual limits } \\
\text { (ASN Decision No. 2009-DC- } \\
\text { 0156 dated 15/09/2009) }\end{array}$ \\
\hline Noble gases & 7,356 & 10,000 \\
- & 297 & 2,000 \\
\hline Tritium & $3.4 \times 10^{-3}$ & 0.5 \\
\hline Carbon 14 & 1.14 & 20 \\
\hline lodides & $7.6 \times 10^{-4}$ & $10^{-2}$ \\
\hline Other $\beta \gamma$-emitters & $4.5 \times 10^{-4}$ & 0.5 \\
\hline$\alpha$-emitters & $6.3 \times 10^{-4}$ & 0.01 \\
& $2.3 \times 10^{-3}$ & $2 \times 10^{-2}$ \\
\hline & $1.7 \times 10^{-4}$ & $5 \times 10^{-3}$ \\
\hline
\end{tabular}

${ }^{(*)}$ Liquid waste released into the chemical waste system. Active liquid waste is also sent to the Saclay and Marcoule treatment plants.

Crisis management measures include "on-site emergency plans", which the facility operators are responsible for activating, and "off-site emergency plans" which are the responsibility of the public authorities. These emergency plans were generally initiated in the early 1980s, following lessons learned from the 1979 Three Mile Island nuclear powerplant accident in the USA ${ }^{216}$. In the case of research reactors operated by CEA, the relevant Director of the centre or his/her representative (or the On-Call Centre Manager outside working hours) is responsible for activating the "on-site emergency plan". In the case of the RHF, this responsibility falls to the Head of Reactor 
Division at Institut Laue-Langevin or his/her deputy (or the On-Call Duty Engineer). Whatever the circumstances, the authorities must be alerted within two hours at the latest.

The on-site emergency plan - some aspects of which are based on a "design study" included in the safety report (see below) - defines organisational measures, intervention methods and the necessary means to be implemented by the facility operator in emergency situations, in order to protect staff, the public and the environment from ionising radiation and to maintain or restore facility safety. It may also specify procedures for implementing measures that are the facility operator's responsibility under the off-site emergency plans (alerting and sheltering in "reflex mode").

If a facility operator implements its on-site emergency plan, it must regularly provide updates on its accident-stricken facility and issue a prognosis anticipating potential developments of the situation. This information is shared and discussed with the French Nuclear Safety Authority and IRSN. One of the "crisis management tools" is the so-called 3D-3P diagnosis and prognosis approach ${ }^{217}$ developed in the 1990s by IPSN and EDF for French nuclear powerplants. In principle, it is applicable to French research reactors. However, it needs to be adapted in a few ways in order to take into account their specific features, including their layout and the number of confinement barriers.

There are other "crisis management tools" (in addition to simplified simulation software - see chapter 11), including summary documents on "standard accidents".

Based on facility characteristics and the associated risks, facility operators responsible for research reactors consider one or more representative accidents (or "standard accidents") and plan crisis management measures to manage such situations. These "standard accidents" are selected from the accidents studied in the safety demonstration and presented in a chapter of the Safety Report ${ }^{218}$ entitled "On-site Emergency Plan Design Study". These "standard accidents" represent the various potential dangers for the facility and are not only radiological dangers (accidents entailing chemical-related consequences may for instance be included). BORAX-type accidents are included in these "standard accidents" for many French research reactors, because they lead to core melt and overpressure in the reactor building, which could cause releases into the environment. Less severe accidents may also be included as "standard accidents" in the on-site emergency plan ${ }^{219}$, including:

- cladding failure on a fuel plate under water, in the reactor core;

- a fuel plate melting under water, in the reactor core;

- a fuel element melting in air in the reactor building during reactor core unloading;

217. The number " 3 " refers to the three confinement barriers in pressurised water reactors.

218. As required by Decree No. 2007-1557 dated 2 November 2007, known as the "procedures" decree.

219. With reference to INSAG-10, a facility operator (in France) may make the decision to activate the on-site emergency plan for accidents that come under defence in depth level 3. (BORAXtype accidents come under level 4). 
- drop of a transport package containing multiple fuel elements, etc.

Some "standard accidents" may assume multiple internal failures or the occurrence of a natural hazard more intense than that considered in facility design.

In the event of an accident involving significant fuel damage, operating staff and researchers in the reactor building and adjacent rooms, such as the control room, may have to be evacuated, due to the dose rates generated. Direct radiation exposure outside the reactor building may also be significant in the event of a core melt incident in air (e.g. core uncovery) or if a fuel element melts during handling in the reactor building. For this reason, French research reactors all have emergency control rooms located at a safe distance from the reactor, given the dose rates that could be generated by the accident-stricken facility. This emergency control room includes information required for accident management (neutron and thermohydraulic parameters in the reactor core, water levels, dose rates, real-time measurement of activity released through the stack, etc.). Some facility systems can also be controlled from this location, such as the emergency ventilation system, which can be used to "manage" atmospheric releases in accident conditions.

Summary documents are produced and updated for different "standard accidents" (by IRSN in particular). These documents specify the potential consequences of the accident, with different variants depending on the weather conditions, time between reactor shutdown and the accident ${ }^{220}$, ventilation systems configuration and possible aggravating factors under the "prognosis" part of the 3D-3P method (e.g. iodine filters in operation or out of service).

Summary sheets describing the research reactors are also available to the crisis management teams, specifying the radiological inventories in the cores and spent fuel storage pools, and the characteristics of confinement barriers and ventilation and filtering systems, etc. These sheets are vital for research reactors, since a relatively small number of people have genuinely in-depth knowledge of these reactors.

The public authorities will analyse the conditions for evacuating or confining local people to their homes, under the "off-site emergency plans". Alongside these plans, short-, medium- or long-term measures to control the consumption or sale of potentially-contaminated foodstuffs are also prepared. The local Prefect is responsible for deciding on the implementations of such measures.

\subsection{Safety aspects for decommissioning research reactors}

Under the applicable regulations, the facility operator responsible for a research reactor now has to present the general principles and provisions for future facility decommissioning in a "decommissioning plan", at the time of the construction licence application. The information in the plan must, where relevant, be updated at the time of the facility commissioning application and at the time of safety reviews. Finally, as for

220. This time period will determine the residual power to be considered, which generally reduces exponentially over time. 
any basic nuclear installation, any facility operator that plans dismantling of a research reactor must file a specific application at the appropriate time.

In France, several research reactors have already been dismantled, including the Strasbourg University Reactor (RUS) and HARMONIE; the SILOE reactor at Grenoble has now been fully dismantled and the ULYSSE reactor in Saclay is at an advanced stage of dismantling. Some other reactors are currently being dismantled. The strategy is to aim for "immediate" dismantling ${ }^{221}$ after final reactor shutdown, in order to draw as much as possible on the skills and knowledge of operators who are still present. The dismantling of the PHENIX reactor has therefore been ordered, following on from the decision by the CEA to shut it down.

Current regulations emphasize the need to take decommissioning into account as early as possible in the life of a facility - from design phase - in order to facilitate dismantling operations and minimise the related risks. With this in mind, it can be noted that the complete removal of the reactor vessel was planned as part of the design of "neutron beam reactors" such as ORPHEE and the RHF.

221. ASN Guide No. 6 (revised version dated 30 August 2016) on INB final shutdown and decommissioining quotes the French Environmental Code, which requires the licensee responsible for operating a basic nuclear installation to "start decommissioning work as quickly as possible, in economically acceptable conditions and in compliance with the principles set forth in Article L. 1333-1 of the Public Health Code and in Article L. 110-1, paragraph II hereof". 